Synergistic chemo-photothermal suppression of cancer with melanin decorated

\title{
MoOx nanosheets
}

Yu Li ${ }^{\mathrm{a}, 1}$, Jianrong Wu ${ }^{\mathrm{a}, 1}$, Gareth R. Williams ${ }^{\mathrm{b}}$, Shiwei Niu ${ }^{\mathrm{a}}$, Jianfeng Zhou ${ }^{\mathrm{c}}$, YanboYang ${ }^{\mathrm{a}}$, Xuejing Zhang ${ }^{\mathrm{a}}$, Zi Fu', Dejian Lid,", Li-Min Zhua ${ }^{\mathrm{a},{ }^{*}}$

${ }^{a}$ College of Chemistry, Chemical Engineering and Biotechnology, Donghua University, Shanghai, 201620, China

b UCL School of Pharmacy, University College London, 29-39 Brunswick Square, London, WC1N 1AX, UK

c Research Center for Analysis and Measurement, Donghua University, Shanghai 201620, People's Republic of China

${ }^{d}$ Department of Orthopedics, Shanghai Pudong Hospital, Fudan University Pudong Medical Center, Shanghai, 201301, China

\section{* Corresponding authors.}

E-mail: 1zhu@dhu.edu.cn (L.-M. Zhu), lidejian880820@163.com (D. Li). Tel: +862167792655 (L.-M. Zhu);

${ }^{1}$ These authors contributed equally.

KEYWORDS: $\mathrm{MoO}_{\mathrm{x}}$, melanin, drug delivery system, photothermal, two-dimensional nanomaterials, synergistic therapy 


\section{ABSTRACT}

Two-dimensional (2D) nanomaterials able to effectively absorb near-infrared (NIR) radiation have shown considerable potential as multifunctional platforms in the treatment of cancer. Here we report a molybdenum dioxide $\left(\mathrm{MoO}_{\mathrm{x}}\right)$-based system for synergistic chemo- and photothermal therapy of cancer. $\mathrm{MoO}_{\mathrm{x}}$ nanosheets were generated via a one-step hydrothermal route, grafted with polyethylene glycol (PEG), and decorated with melanin (Mel), with successful functionalization confirmed by IR spectroscopy. The mean diameter and thickness of the MoOx particles are found to be $302 \pm 34 \mathrm{~nm}$ and $19 \pm 2 \mathrm{~nm}$ using atomic force microscopy. The hydrodynamic size of the MoOx nanosheets was $105 \pm 17 \mathrm{~nm}$, and the final MoOx-PEG-Mel-DOX formulation had a diameter of $161 \pm 26 \mathrm{~nm})$. The $\mathrm{MoO}_{\mathrm{x}}-\mathrm{PEG}-\mathrm{Mel}$ nanosheets efficiently convert NIR light to heat, possessing a photothermal conversion efficiency of $61.7 \%$. They can also be loaded with doxorubicin (DOX), giving a high drug loading (325.6 mg DOX / g MoO ${ }_{\mathrm{x}}$-PEG-Mel). MoO $\mathrm{x}$-PEG-Mel-DOX shows DOX release influenced by $\mathrm{pH}$ and NIR irradiation. Systematic in vitro and in vivo evaluations reveal that synergistic chemo- and photothermal therapy using $\mathrm{MoO}_{\mathrm{x}}-\mathrm{PEG}-\mathrm{Mel}-\mathrm{DOX}$ can completely eradicate a tumor, with no observable off-target cytotoxicity. This is the first report of the fabrication of enhanced photothermal agents by combining $\mathrm{MoO}_{\mathrm{x}}$ nanosheets and a natural product. This work proffers a strategy for efficiently treating cancer, as well as potentially extending the photothermal applications of 2D nanomaterials by surface melanin functionalisation. 


\section{INTRODUCTION}

Cancer remains a major healthcare burden worldwide ${ }^{1}$. A variety of treatments, including chemotherapy, surgical resection and laser treatment are available, but typically these come with undesirable side-effects. For instance, chemotherapy is a vital tool for clinicians but has inevitable toxic side effects on healthy tissues and organs, and long-term therapy can lead to the development of resistance to the drug. New treatments are required to ameliorate these issues. Near-infrared (NIR) light-induced photothermal therapy (PTT) has recently emerged as a powerful treatment modality due to its high selectivity and minimal invasiveness ${ }^{2-9}$. PTT requires photothermal agents to convert NIR irradiation into heat and thereby ablate a tumor. Since NIR can be focused locally on the tumor site, this approach can reduce off-target effects. If the delivery system containing the photothermal agent (PTA) is of an appropriate size then the enhanced permeability and retention (EPR) effect allows it to also be selectively accumulated in the tumor area ${ }^{10-11}$. However, the targeting which can be achieved by PTT is imperfect, and effects such as uneven thermal distribution can cause damage to nearby healthy tissue ${ }^{12-13}$. In addition, therapeutic outcomes are constrained by the limited penetration depth of NIR light.

Research into two-dimensional (2D) materials accelerated dramatically after the discovery of graphene in 2004. Over the past decade, a large number of single or multilayer two-dimensional materials have been explored in many different fields, such as photoelectronics, energy storage, and biomedicine. The latter includes applications in photothermal therapy, and a range of PTAs based on two-dimensional (2D) 
nanomaterials have been reported ${ }^{14-17}$. Multifunctional drug delivery systems based on such 2D systems include those fabricated from graphene derivatives ${ }^{18}, \mathrm{MoS}_{2}{ }^{15}$ or $\mathrm{WS}_{2}$ 19. All these materials exhibit effective absorption in the NIR region $(\lambda=650-1000 \mathrm{~nm})$, and thus can induce local hyperthermia upon exposure to NIR light ${ }^{20}$. Loading small molecule drugs onto PTA nanomaterials can further enhance therapeutic efficiency, as a result of photothermally-mediated drug release ${ }^{16,21-22}$.

NIR absorption by nonstoichiometric metal chalcogenides is related to the local surface plasmon resonance ${ }^{23-25}$. Non-stoichiometric molybdenum oxide-based systems $\left(\mathrm{MoO}_{\mathrm{x}}\right)$ are appealing candidate materials for plasmon-based biological applications owing to their excellent biocompatibility, simple routes to preparation, and significant NIR absorption ${ }^{21,26-27}$. In this work, we explored the effects of coupling $\mathrm{MoO}_{\mathrm{x}}$ with melanin (Mel), a natural biological pigment ${ }^{28}$ with strong absorption in the NIR region 29-31. We used a simple, cost-effective, single-step route to prepare $\mathrm{MoO}_{\mathrm{x}}$, and then modified the resultant nanosheets with poly(ethylene glycol) (PEG) to enhance stability in the physiological environment ${ }^{32}$. To improve the photothermal conversion efficacy (PTCE) of the $\mathrm{MoO}_{\mathrm{x}}$-PEG nanosheets, Mel was also added to their surfaces. The chemotherapeutic doxorubicin hydrochloride (DOX) was finally loaded onto the system. The nanoplatform was characterized in detail, and its drug release behavior, in vitro toxicity, and in vivo efficacy probed. The experimental strategy underlying the work is illustrated in Scheme 1.

\section{RESULTS AND DISCUSSION}


Synthesis and characterization of $\mathrm{MoO}_{\mathbf{x}}$ nanocomposites. Scheme 1 illustrates the schematic procedure employed for the fabrication of $\mathrm{MoO}_{\mathrm{x}}$-based drug delivery systems in this work. First, molybdenum oxide nanosheets were prepared according to the literature with some modifications ${ }^{33}$. The surface was then modified with PEG before Mel was added and DOX loaded onto the surface of the nanosheets, resulting in $\mathrm{MoO}_{\mathrm{x}}$-PEG-Mel-DOX. The TEM data (Figure 1a) reveal irregularly shaped sheet structures form after exfoliation. The mean diameter and thickness of the $\mathrm{MoO}_{\mathrm{x}}$ particles are found to be $302 \pm 34 \mathrm{~nm}$ and $19 \pm 2 \mathrm{~nm}$ using AFM (Figure 1b,c). The hydrodynamic size of the $\mathrm{MoO}_{\mathrm{x}}$ nanosheets was $105 \pm 17 \mathrm{~nm}$ (Figure 1d). It is unusual for hydrodynamic sizes to be smaller than those from AFM, but we attribute this to the dynamic light scattering experiment assuming the particles are spherical, whereas they actually take the form of platelets. Thus, the hydrodynamic size is intermediate between the true diameter and thickness of the particles.

The valence state of Mo and chemical composition of the $\mathrm{MoO}_{\mathrm{x}}$ nanosheets were determined by XPS. The XPS survey spectrum of $\mathrm{MoO}_{\mathrm{x}}$ (Figure 2a) indicates the presence of Mo, O, C, and possibly $\mathrm{N}$ (the latter two expected to be from residual oleylamine). Upon curve fitting and deconvolution, the Mo 3d region reveals four key peaks: $\mathrm{Mo}^{\mathrm{VI}} 3 \mathrm{~d}_{3 / 2}, \mathrm{Mo}^{\mathrm{V}} 3 \mathrm{~d}_{3 / 2}, \mathrm{Mo}^{\mathrm{VI}} 3 \mathrm{~d}_{5 / 2}$, and $\mathrm{Mo}^{\mathrm{V}} 3 \mathrm{~d}_{5 / 2}$ (Figure 2b). The sharp peaks at 234.1 and $230.9 \mathrm{eV}$ correspond to the $3 \mathrm{~d}_{3 / 2}$ and $3 \mathrm{~d}_{5 / 2}$ bands of $\mathrm{Mo}^{5+}$ respectively. The broader peaks at 235.7 and $232.5 \mathrm{eV}$ can be attributed to $\mathrm{Mo}^{6+} 3 \mathrm{~d}_{3 / 2}$ and $3 \mathrm{~d}_{5 / 2}{ }^{34-36}$. From calculating the area ratios of $\mathrm{Mo}^{5+}$ and $\mathrm{Mo}^{6+}$ the contents of $\mathrm{Mo}^{5+}$ and $\mathrm{Mo}^{6+}$ in $\mathrm{MoO}_{\mathrm{x}}$ are estimated at $49.6 \%$ and $50.4 \%$, giving a mean oxidation state of +5.5 and an 
empirical formula of $\mathrm{MoO}_{2.75}$.

The small angle XRD data (Figure S1, Supporting Information) agree with those previously reported for $\mathrm{MoO}_{\mathrm{x}}{ }^{33}$. However, neither this nor the wide angle pattern (Figure S2) match with any of the crystal structures for binary $\mathrm{Mo} / \mathrm{O}$ compounds reported in the ICSD. The presence of regularly spaced reflections (at $2.5,5.0,7.5^{\circ}$ ) indicate the presence of a layered structure with basal reflections at $c a .35 .3,17.7$, and $11.8 \AA$. This suggests that the material fabricated comprises an O-deficient $\mathrm{MoO}_{3}$ structure (the latter is known to be layered). The very large interlayer spacing can be attributed to the incorporation of oleylamine between the $\mathrm{MoO}_{\mathrm{x}}$ layers. The end-to-end distance of oleylamine is around $22 \AA$, and therefore a d-spacing of $\sim 35 \AA$ is consistent with the presence of an intertwined bilayer of oleylamine molecules between the $\mathrm{MoO}_{\mathrm{x}}$ layers, with the $\mathrm{NH}_{2}$ groups interacting through $\mathrm{H}$-bonding with the $\mathrm{O}$ atoms in the layers.

The functionalization of $\mathrm{MoO}_{\mathrm{x}}$ with PEG and Mel and subsequent loading of DOX were evaluated by IR and UV-vis spectroscopy, and through zeta potential measurements. IR spectra are presented in Figure 3a. The peaks at 640 and $880 \mathrm{~cm}^{-1}$ in the spectrum of $\mathrm{MoO}_{\mathrm{x}}$ correspond to Mo-O-Mo vibrations, and there is additionally a band at $950 \mathrm{~cm}^{-1}$ from $\mathrm{Mo}=\mathrm{O}{ }^{37-41} \cdot \mathrm{CH}_{2}$ vibrations can be seen at around $2950 \mathrm{~cm}^{-1}$ and $1450 \mathrm{~cm}^{-1}$ from the oleylamine in the system. The IR spectrum of PEG shows particularly distinct bands at 1060 and $1100 \mathrm{~cm}^{-1}$ from $-\mathrm{C}-\mathrm{O}-\mathrm{C}$ - vibrations. Both can be seen in the $\mathrm{MoO}_{\mathrm{x}}-\mathrm{PEG}$ spectrum, indicating successful modification. Melanin has $\mathrm{C}=\mathrm{O}$ functional groups, which result in bands at 1705 and $1607 \mathrm{~cm}^{-1}$. These characteristic 
peaks are also observed with both $\mathrm{MoO}_{\mathrm{x}}$-PEG-Mel and $\mathrm{MoO}_{\mathrm{x}}-\mathrm{PEG}-\mathrm{Mel}-\mathrm{DOX}$, suggesting successful functionalization with Mel.

As would be intuitively expected, the particle size (Figure 1d) becomes increasingly large at each functionalization step, with the final MoOx-PEG-Mel-DOX nanosheets being $163 \pm 27 \mathrm{~nm}$ in size. Zeta potential measurements (Figure $3 \mathrm{~b}$ ) found that the potential of $\mathrm{MoO}_{\mathrm{x}}$ is $-6.3 \mathrm{mV}$, but this declines to $-26.1 \mathrm{mV}$ after the addition of PEG because of the existence of ester group in mPEG-DSPE. The potential further decreases to $-43.1 \mathrm{mV}$ after Mel functionalization, as a result of the presence of ionizable $\mathrm{COOH}$ groups in Mel. After DOX is loaded, the zeta potential rises to $+17.2 \mathrm{mV}$ because of the amine groups in DOX. The serial changes in zeta potential following each step in the nanocomposite construction process indicate the successful formation of $\mathrm{MoO}_{\mathrm{x}}-\mathrm{PEG}-$ Mel-DOX.

UV-vis-NIR spectra (Figure 3c) reveal that the MoOx systems absorb strongly in the NIR region as expected. The characteristic absorption peaks of DOX at $480 \mathrm{~nm}$ and at $200-250 \mathrm{~nm}$ are present in the UV-vis spectrum of $\mathrm{MoO}_{\mathrm{x}}-\mathrm{PEG}-\mathrm{Mel}-\mathrm{DOX}$, demonstrating successful drug loading. A range of $\mathrm{MoO}_{\mathrm{x}}-\mathrm{PEG}-\mathrm{Mel}$ : DOX ratios were explored, and the DOX loading onto the nanosheets determined from UV-vis-NIR spectroscopy (Figure S5). As the ratio of DOX: $\mathrm{MoO}_{\mathrm{x}}-\mathrm{PEG}-\mathrm{Mel}$ increased from 1:4 to $1: 1$, the DOX loading capacity increased, reaching a saturation level of $32.5 \%$ at a ratio of $1: 1$. This formulation was used for all other studies. The loading capacity noted here is rather greater than a previous report by Zhang et al. (who obtained a loading of 151.4 mg per gram of a $\mathrm{MoS}_{2}-\mathrm{PEG}$ nanocomposite) and close to that reported for graphdiyne 
$(38 \%)^{42-43}$. The loading observed here is significantly improved over other a range of other delivery systems which have been explored in the literature, such as molecularly imprinted polymers $(7.08 \%)$, polyprodrug nanoparticles $(13 \%)$, or mesoporous silica nanoparticles $(5.8 \%)^{44-46}$.

In vitro drug release. $\mathrm{DOX}$ release was studied at two different $\mathrm{pH}$, with or without laser irradiation (Figure 3d). The cumulative drug release reached $21.9 \%$ and $62.4 \%$ at $\mathrm{pH} 7.4$ and $\mathrm{pH}$ 5.0, indicating that drug release from $\mathrm{MoO}_{\mathrm{x}}-\mathrm{PEG}-\mathrm{Mel}-\mathrm{DOX}$ is $\mathrm{pH}$ responsive. This can be ascribed to the amino group of DOX being ionized in acidic conditions, increasing its solubility and encouraging drug release ${ }^{47}$. With the application of NIR irradiation, DOX release reaches $74.2 \%$ in the acidic environment, again higher than the $34.6 \%$ seen in neutral conditions. This increase in release upon NIR exposure arises because of hyperthermia being induced by laser irradiation. This increases the vibrational energy of both the $\mathrm{MoO}_{\mathrm{x}}$ nanosheets and $\mathrm{DOX}$, thereby reducing the strength of interactions between the two and accelerating drug release. Because the tumor microenvironment has a lower $\mathrm{pH}$ than that of normal tissue, such a drug delivery system is likely to be effective in targeted cancer chemotherapy ${ }^{42,48}$.

Photothermal effects. PTT data are presented in Figure 4. The temperature changes of $\mathrm{MoO}_{\mathrm{x}}-\mathrm{PEG}$ and $\mathrm{MoO}_{\mathrm{x}}$-PEG-Mel suspensions as a function of time were recorded (Figure 4a) and the PTCE of $\mathrm{MoO}_{\mathrm{x}}-\mathrm{PEG}$ and $\mathrm{MoO}_{\mathrm{x}}$-PEG-Mel evaluated under identical conditions (concentration: $1 \mathrm{mg} / \mathrm{mL}$; power: $1 \mathrm{~W} / \mathrm{cm}^{2}$ for $5 \mathrm{~min}$ ). The PTCE $(\eta)$ of $\mathrm{MoO}_{\mathrm{x}}-\mathrm{PEG}$ and $\mathrm{MoO}_{\mathrm{x}}$-PEG-Mel are respectively 44\% (Figure S3) and 61.7\% (Figure 4b). These values are notably higher than reported data for other PTAs (e.g. graphene 
oxide at $25 \%$, antimony quantum dots at $45.5 \%$, or a black phosphorus analogue compound at $39.3 \%)^{49-51}$.

The temperature changes for aqueous suspensions of $\mathrm{MoO}_{\mathrm{x}}-\mathrm{PEG}-\mathrm{Mel}-\mathrm{DOX}$ at different concentrations were next measured (Figure 4c). Compared with pure water, the $\mathrm{MoO}_{\mathrm{x}}$-PEG-Mel-DOX dispersions display increasing temperatures as the concentration is increased. Temperatures can reach $67.9^{\circ} \mathrm{C}$ after laser irradiation for 5 $\min \left(1 \mathrm{mg} / \mathrm{mL}\right.$; power: $\left.1 \mathrm{~W} / \mathrm{cm}^{2}\right)$. Laser power density-dependent temperature increases are also seen with $\mathrm{MoO}_{\mathrm{x}}$-PEG-Mel-DOX suspensions (Figure 4d). The enhancement in the photothermal efficiency after decoration of $\mathrm{MoO}_{\mathrm{x}}$ with $\mathrm{Mel}$ is clear from the thermal imaging data (Figure 4e). In previous studies with similar systems rather lower PTCEs have been observed, with 22.6\% reported for $\mathrm{MoO}_{3-\mathrm{x}}$ hollow nanospheres and $27.3 \%$ for $\mathrm{MoO}_{\mathrm{x}}$ nanoparticles ${ }^{21,27}$. The $\mathrm{MoO}_{\mathrm{x}}-\mathrm{PEG}-\mathrm{Mel}-\mathrm{DOX}$ system can reach a higher temperature in a reduced time period, and thus can potentially kill tumor cells more quickly while reducing damage to normal tissues ${ }^{52-53}$.

For therapeutic applications, the stability of the system over repeated cycles of NIR irradiation is crucial. We find that $\mathrm{MoO}_{\mathrm{x}}$-PEG-Mel-DOX maintains its potent PTT properties, and a strong and unchanged temperature response is observed over five cycles of illumination (Figure S4). Overall, these findings indicate that the $\mathrm{MoO}_{\mathrm{x}}-\mathrm{PEG}-$ Mel-DOX nanomaterial has good prospects for use in photothermal therapy.

Intracellular DOX release. CLSM data are presented in Figure 5a. The presence of both DOX (red) and DAPI (blue) fluorescence, the images show that MoOx-PEG-MelDOX could be extensively taken up by cancer cells. In contrast, the free DOX showed 
relatively weak intracellular red fluorescence compared with the MoOx-PEG-DOX groups, with or without NIR laser irradiation. This can be ascribed to increased uptake of MoOx-PEG-Mel nanosheets. For the NIR-treated MoOx-PEG-Mel-DOX group, the intracellular red fluorescence was significantly enhanced, which is expected to result from the hyperthermia generated by the NIR laser. This causes the cell membrane to become slightly damaged, and the nanomaterial uptake to increase. Hyperthermia also promotes the release of DOX from the drug delivery system. Further investigation of MoOx-PEG-Mel-DOX internalization by 4T1 cells was performed with the aid of flow cytometry. Figure S6 shows that the intracellular DOX fluorescence intensity of cells treated with MoOx-PEG-Mel-DOX after laser irradiation was significantly stronger than for those cells not receiving a laser treatment, confirming that NIR-facilitated the intracellular release of DOX and uptake of MoOx-PEG-Mel-DOX nanosheets.

In vitro cell viability. The cytocompatibility of $\mathrm{MoO}_{\mathrm{x}}-\mathrm{PEG}$ and $\mathrm{MoO}_{\mathrm{x}}-\mathrm{PEG}-\mathrm{Mel}$ with 4T1 cells was investigated using the MTT assay. As can be seen from Figure 5b, cell survival rates are high, and even at $200 \mu \mathrm{g} / \mathrm{mL}$ the viability is $>80 \%$. The carrier materials hence appear to be very biocompatible. We next explored the potential of the systems in in vitro photothermal and chemotherapeutic cell killing experiments. The results can be found in Figure 5c. In all cases, dose-dependent cytotoxic effects are seen. Free DOX is the least effective of the treatments, with cell viability still at $c a .40 \%$ when a concentration of $10 \mu \mathrm{g} / \mathrm{mL}$ was used. $\mathrm{MoO}_{\mathrm{x}}$-PEG-Mel-DOX without laser irradiation causes somewhat more cell death than free DOX. The application of NIR irradiation markedly increases cell death, with both $\mathrm{MoO}_{\mathrm{x}}-\mathrm{PEG}-\mathrm{Mel}$ and $\mathrm{MoO}_{\mathrm{x}}-\mathrm{PEG}$ 
and NIR administration leading to greater cell death than the DOX-containing systems without NIR exposure. Still greater cell death is observed when the $\mathrm{MoO}_{\mathrm{x}}-\mathrm{PEG}-\mathrm{Mel}-$ DOX system is combined with NIR: this treatment gave the lowest cell viability values. When the concentration of DOX was $10 \mu \mathrm{g} / \mathrm{mL}$, the viability of cells given free DOX and $\mathrm{MoO}_{\mathrm{x}}-\mathrm{PEG}-\mathrm{Mel}-\mathrm{DOX}$ were $39 \%$ and $30.7 \%$. Those treated with $\mathrm{MoO}_{\mathrm{x}}-\mathrm{PEG}+\mathrm{NIR}$ had a survival rate of $24.9 \%$, while the $\mathrm{MoO}_{\mathrm{x}}-\mathrm{PEG}-\mathrm{Mel}$ group viability was $8.1 \%$ and the synergistic treatment led to only $2.3 \%$ cell survival. The half maximal inhibitory concentration $\left(\mathrm{IC}_{50}\right)$ of MoOx-PEG-Mel-DOX is $2.31 \mu \mathrm{g} \mathrm{mL} \mathrm{L}^{-1}$, much smaller than the free $\operatorname{DOX}\left(6.27 \mu \mathrm{g} \mathrm{mL}^{-1}\right)$. This is presumably a result of the greater extent of uptake of the MoOx-PEG-Mel-DOX nanosheets. For the combined treatment comprising MoOxPEG-Mel-DOX with NIR irradiation, the $\mathrm{IC}_{50}$ is $0.028 \mu \mathrm{g} \mathrm{mL}-1$, as a result of the synergistic chemo-photothermal therapy.

To further evaluate the ability of the nanocomposites to kill cancer cells, 4T1 cells were stained with CA and PI. This permits us to distinguish between live (green) and apoptotic (red) cells (Figure 5d). Cells treated with PBS showed only very small amounts of cell death, while increased apoptosis was noted with cells exposed to other treatments. The greatest extent of cell death was observed with MoOx-PEG-Mel-DOX and NIR laser irradiation. The NIR both causes temperature increases through photothermal conversion, and also weakens the interactions between DOX and the $\mathrm{MoO}_{\mathrm{x}}$ carrier ${ }^{42}$. This synergistic effect leads to the greatest extent of cell death when both PTT and chemotherapy are applied.

Compared with previously published studies using $\mathrm{MoS}_{2}$ as the PTA ${ }^{16,42}$, the $\mathrm{MoO}_{\mathrm{x}}$ 
composites here are more potent in inducing cell death. With NIR irradiation and an equivalent DOX concentration of $10 \mu \mathrm{g} / \mathrm{mL}, \mathrm{MoS}_{2}$ materials leave more than $10 \%$ of cells alive, while here the survival rate was only $2.3 \%$ with an analogous treatment. This can be attributed to the higher PTCE of the $\mathrm{MoO}_{\mathrm{x}}$ nanoplatform and its greater drug loading capacity.

In vivo antitumor efficacy. $4 \mathrm{~T} 1$ tumor-bearing mice were randomly assigned to one of five groups: (I) control (saline); (II) free DOX; (III) $\mathrm{MoO}_{\mathrm{x}}-\mathrm{PEG}-\mathrm{Mel}-\mathrm{DOX}$; (IV) $\mathrm{MoO}_{\mathrm{x}}-\mathrm{PEG}-\mathrm{Mel}+\mathrm{NIR}$; and, (V) $\mathrm{MoO}_{\mathrm{x}}$-PEG-Mel-DOX+NIR. During the treatment period, there was no significant weight loss in animals treated with the $\mathrm{MoO}_{\mathrm{x}}$ nanocomposites, indicating a lack of toxicity (Figure 6a). In contrast, a steady loss in weight was seen in the free DOX group. This effect arises owing to the off-target effects of the drug. The sizes of the tumors grow continuously throughout the experiment when the mice were given DOX or saline (Figure 6b), and small increases are seen with $\mathrm{MoO}_{\mathrm{x}}$-PEG-Mel-DOX and $\mathrm{MoO}_{\mathrm{x}}-\mathrm{PEG}-\mathrm{Mel}+\mathrm{NIR}$ treatment. A decline in the tumor volume to virtually zero is noted in the $\mathrm{MoO}_{\mathrm{x}}-\mathrm{PEG}-\mathrm{Mel}-\mathrm{DOX}+\mathrm{NIR}$ group. The animals were euthanized after 21 days and the tumors exercised and photographed (Figure 6c). These images verify the results in Figure $6 \mathrm{~b}$, with the smallest tumors being from mice receiving $\mathrm{MoO}_{\mathrm{x}}$-PEG-Mel-DOX+NIR. Kaplan-Meier survival curves (Figure 6d) show that the survival time of the mice given synergistic PTT-chemotherapy was markedly longer than the other groups.

Histological analysis. After the treatment, the major organs and tumors of the mice were excised and H\&E staining used to investigate the in vivo toxicity and therapeutic 
effects of the different groups. Compared to the control group, large areas of necrotic and apoptotic cells in the tumor area (brown dots) can be observed in the synergistic treatment group by TUNEL staining (Figure 6e). The same conclusions can be drawn from the hematoxylin and eosin (H\&E) staining (Figure 6e).

There was no significant inflammation, apoptosis or necrosis observed in sections of the major organs ( spleen, liver, heart, lung and kidney) in the case of the groups treated with the nanosheets. In the images from the free DOX group the the glomerular cells of the kidney show visible congestion, and also slight focal inflammation in the liver (indicating hepatocellular vesicular steatosis) (Figure 7) ${ }^{48,54}$. These findings reveal that the $\mathrm{MoO}_{\mathrm{x}}$-PEG-Mel-DOX nanoplatform has low off-target toxicity and good biocompatibility, which renders it appropriate for prolonged treatment regimens such as those required to treat cancer.

Biodistribution. A biodistribution study was performed by measuring the Mo concentrations at selected time points after the injection of $\mathrm{MoO}_{\mathrm{x}}-\mathrm{PEG}-\mathrm{Mel}-\mathrm{DOX}$ (see Figure S7). After one day, Mo is mainly concentrated in the liver, spleen and lungs. This arises, as a result of recognition of the nanosheets by the reticuloendothelial system. The presence of Mo in the major organs rapidly decreases with time, and reaches a very low level on the seventh day. This suggests that the MoOx nanosheets can be quickly excreted after administration, and do not accumulate in vivo.

Discussion. The new PTT system developed in this work has a number of advantages over others previously reported in the literature. First, compared with the cumbersome multi-step process required to generate $\mathrm{MoS}_{2}$ and $\mathrm{Ti}_{3} \mathrm{C}_{2}$ and the low yield typically seen 
with antimony quantum dots, the $\mathrm{MoO}_{\mathrm{x}}$ system is prepared by a facile hydrothermal approach and can be produced in bulk. Compared with other $\mathrm{MoO}_{\mathrm{x}}$ materials that have been reported ${ }^{21,27}$, the $\mathrm{MoO}_{\mathrm{x}}$-PEG-Mel-DOX system has a higher PTCE, so the temperature can be raised more rapidly to kill tumor cells and reduce damage to normal tissues. DOX release is responsive both to $\mathrm{pH}$ and NIR irradiation, meaning that the systems have the potential to be used to specifically target tumor tissue. The literature is clear that $\mathrm{MoO}_{\mathrm{x}}$ materials have good in vivo biocompatibility and better biodegradability than $\mathrm{MoS}_{2} 26-27,33,55$, which concurs with the findings from this study. Overall therefore, it appears that the $\mathrm{MoO}_{\mathrm{x}}$ systems have great potential for targeted cancer therapeutics.

\section{CONCLUSIONS}

Here we report melanin decorated $\mathrm{MoO}_{\mathrm{x}}$ nanosheets prepared via a one-pot hydrothermal method. These were loaded with doxorubicin (DOX) and explored for combined photothermal (PTT)-chemotherapy. The combination of melanin and $\mathrm{MoO}_{\mathrm{x}}$ endows the platform with a high photothermal conversion efficiency (61.7\%). The drug-loaded $\mathrm{MoO}_{\mathrm{x}}$-PEG-Mel-DOX nanoparticles possess a uniform size $(163 \pm 13 \mathrm{~nm})$ and high drug loading capacity $\left(325.6 \mathrm{mg} / \mathrm{g} \mathrm{MoO}_{\mathrm{x}}-\mathrm{PEG}-\mathrm{Mel}\right)$. Drug release from $\mathrm{MoO}_{\mathrm{x}}$-PEG-Mel-DOX was responsive to both $\mathrm{pH}$ and NIR laser irradiation. In vitro experiments demonstrate that the $\mathrm{MoO}_{\mathrm{x}}$-PEG-Mel-DOX nanoplatform effectively kills breast cancer cells via synergistic PTT and chemotherapy. In addition, in vivo therapeutic evaluations in a murine xenograft breast cancer model revealed a complete 
suppression of tumor growth when mice were given synergistic chemo/PTT therapy. Systematic in vivo biocompatibility assays showed $\mathrm{MoO}_{\mathrm{x}}$-PEG-Mel-DOX to have very good biocompatibility, with no off-target toxicity observed. Overall, the findings indicate that the $\mathrm{MoO}_{\mathrm{x}}$-PEG-Mel-DOX nanoplatform has great potential in cancer therapy.

\section{EXPERIMENTAL SECTION}

Materials and reagents: Ammonium molybdate tetrahydrate $\left[\left(\mathrm{NH}_{4}\right)_{6} \mathrm{Mo}_{7} \mathrm{O}_{24} \cdot 4 \mathrm{H}_{2} \mathrm{O}\right]$, oleylamine (80-90\%), and doxorubicin hydrochloride (DOX) were obtained from Aladdin Co., Ltd. Melanin, propidium iodide (PI), 3-(4,5-dimethylthiazol-yl)-2,5-diphenyltetrazolium bromide (MTT), calcein-AM (CA), propidiumiodide (PI) and phosphate buffered saline (PBS) were supplied by Sigma Aldrich. Polyethylene glycol (mPEG-DSPE, Mw = 2000) was purchased from Shanghai YaYi Co., Ltd. Cyclohexane and aqueous hydrochloric acid (37.5 wt \%) were provided by the Sinopharm Chemical Reagent Co., Ltd. 4T1 cells were obtained from the Type Culture Collection of the Chinese Academy of Sciences. Fetal bovine serum (FBS), Dulbecco's Modified Eagle Medium (DMEM), trypsin-EDTA, penicillin and streptomycin were acquired from Gibco. A hematoxylin and eosin staining kit was sourced from Shanghai Weiao Biotechnology Co, and a terminal deoxynucleotidyl transferase dUTP nick end labeling (TUNEL) apoptosis detection kit from Beyontime. Distilled water was employed throughout.

Synthesis of $\mathrm{MoO}_{\mathbf{x}}$ nanosheets. These were prepared through a simple 
hydrothermal process. Ammonium molybdate (3 g) was dispersed in distilled water (30 $\mathrm{mL})$, while hydrochloric acid $(1.5 \mathrm{~mL}, 1 \mathrm{~mol} / \mathrm{L})$ and oleylamine $(2 \mathrm{~g})$ were dissolved in cyclohexane $(10 \mathrm{~mL})$. The two liquids were then mixed slowly under stirring for 30 min, resulting in the formation of a white solid. The dispersion was placed in an autoclave $(50 \mathrm{~mL})$ and heated at $180^{\circ} \mathrm{C}$ for $14 \mathrm{~h}$. A blue precipitate was obtained after this hydrothermal process. The precipitate was washed with chloroform and ethanol and recovered by centrifugation.

Preparation of $\mathrm{MoO}_{\mathbf{x}}$-PEG nanosheets. For PEGylation, $10 \mathrm{mg}$ of $\mathrm{MoO}_{\mathrm{x}}$ was finely ground in a pestle and mortar and then mixed with $40 \mathrm{~mL}$ of chloroform. This dispersion was cooled in an ice bath and a probe sonicator (SL-400sS, Nanjing Shunliu Instruments) used to exfoliate the solid. Next, $50 \mathrm{mg}$ of mPEG-DSPE was dispersed into the $\mathrm{MoO}_{\mathrm{x}}$ suspension. The mixture obtained was stirred at room temperature for $12 \mathrm{~h}$. The chloroform was removed by rotary evaporation, and the residual solid dispersed in deionized water under sonication. $\mathrm{MoO}_{\mathrm{x}}-\mathrm{PEG}$ was isolated by centrifugation before being washed with distilled water $(30 \mathrm{~mL})$.

Preparation of $\mathrm{MoO}_{\mathbf{x}}$-PEG-Mel nanosheets. $\mathrm{MoO}_{\mathrm{x}}$-PEG nanosheets $(20 \mathrm{mg}$ ) were dispersed into distilled water $(30 \mathrm{~mL})$ and $\mathrm{Mel}(4 \mathrm{mg})$ was added under ultrasonication, followed by stirring for $12 \mathrm{~h}$. The $\mathrm{MoO}_{\mathrm{x}}-\mathrm{PEG}-\mathrm{Mel}$ product was isolated by centrifugation and then washed with distilled water $(30 \mathrm{~mL})$ three times.

Drug loading. DOX (20 mg) was dissolved in distilled water $(40 \mathrm{~mL})$ and $\mathrm{MoO}_{\mathrm{x}}-$ PEG-Mel $(20 \mathrm{mg}$ ) added, with ultrasonication performed for $5 \mathrm{~min}$ to form a homogeneous suspension. This was followed by stirring for $12 \mathrm{~h}$ in the dark. The solid 
product was separated by centrifugation and purified by washing with distilled water $(30 \mathrm{~mL})$. The supernatants were collected and used to quantify the loading capacity of the system via UV-vis spectroscopy at $480 \mathrm{~nm}$.

Materials characterization. The particle habit of $\mathrm{MoO}_{\mathrm{x}}$ was studied on a transmission electron microscope (TEM; JEM-2100, JEOL). The dimensions of the $\mathrm{MoO}_{\mathrm{x}}$-PEG nanosheets were quantified using a 5500 atomic force microscope (AFM; Agilent). A BI-200SM instrument (Brookhaven) was employed to collect dynamic light scattering (DLS) data, and a ZS90 Zetasizer (Malvern Instruments) for zeta potential measurements. UV-vis spectra were collected on a Shanghai JingHua Instruments UV1800 spectrophotometer. IR spectra were obtained with the aid of a Nexus 870 spectrometer (Nicolet Instruments Inc). X-ray diffraction (XRD) patterns were obtained on a Bruker D8 Advance diffractometer. This is supplied with $\mathrm{Cu} \mathrm{K} \alpha$ radiation $(\lambda=1.5418 \AA)$. The chemical composition of $\mathrm{MoO}_{\mathrm{x}}$ was explored by X-ray photoelectron spectroscopy (XPS), and spectra produced using an Escalab 250Xi instrument. The PTCE of the $\mathrm{MoO}_{\mathrm{x}}-\mathrm{PEG}$ and $\mathrm{MoO}_{\mathrm{x}}$-PEG-Mel nanosheets were quantified with an $808 \mathrm{~nm}$ laser apparatus (Shanghai Xilong Optoelectronics Technology Co) and the temperature of the dispersion recorded by a thermocouple connected to a digital thermometer (DT-8891E, Shenzhen Everbest Machinery Industry).

Photothermal effects. To explore the photothermal effects of $\mathrm{MoO}_{\mathrm{x}}-\mathrm{PEG}-\mathrm{Mel}-\mathrm{DOX}$, various concentrations of the samples were irradiated $\left(808 \mathrm{~nm}, 1.0 \mathrm{~W} / \mathrm{cm}^{2}\right)$ for $5 \mathrm{~min}$. The effect of laser power density was investigated by exposing a suspension of $\mathrm{MoO}_{\mathrm{x}^{-}}$ 
PEG-Mel-DOX $(1.0 \mathrm{mg} / \mathrm{mL})$ to different densities from 0.25 to $1.50 \mathrm{~W} / \mathrm{cm}^{2}$. Water was employed as a control and exposed to the same conditions. The NIR laser stability of $\mathrm{MoO}_{\mathrm{x}}$-PEG-Mel-DOX was evaluated under irradiation for $5 \mathrm{~min}\left(1.0 \mathrm{~W} / \mathrm{cm}^{2}\right)$ over five laser on-off cycles. In all cases, temperature changes of the suspension were recorded through an infrared thermal imaging system (FLIR A300, Shanghai Spectrum Electronics Technology Co). The volume of dispersion used for each experiment was $200 \mu \mathrm{L}$, and therefore the temperature of the suspension can be assumed to be constant throughout. The PTCE was calculated using the equation:

$$
\eta=\frac{h S\left(T_{\max }-T_{a m}\right)-Q_{0}}{I\left(1-10^{-A}\right)}
$$

$\mathrm{S}$ and $\mathrm{h}$ represent the surface area and the heat transfer coefficient. $\mathrm{T}_{\max }$ is the equilibrium temperature and $\mathrm{T}_{\mathrm{am}}$ the ambient temperature, $\mathrm{Q}_{0}$ the heat absorption of the quartz container, I the laser power density $(250 \mathrm{~mW})$, and A the absorbancy of the samples at $808 \mathrm{~nm}^{56}$.

In vitro drug release. $3 \mathrm{~mL}$ of a suspension of $\mathrm{MoO}_{\mathrm{x}}-\mathrm{PEG}-\mathrm{Mel}-\mathrm{DOX}(1.0 \mathrm{mg} / \mathrm{mL})$ in PBS (pH 7.4 or 5.0) was placed in a dialysis bag $(\mathrm{MWCO}=8-10 \mathrm{kDa})$ and dialyzed against PBS at the same $\mathrm{pH}(40 \mathrm{~mL})$ under stirring. Periodically, $1 \mathrm{~mL}$ aliquots were collected and an equal volume of fresh-preheated PBS was added. The concentration of DOX in the release aliquots was quantified at $480 \mathrm{~nm}$ by UV-vis spectroscopy. Where laser treatment was undertaken, the formulations were irradiated for $5 \min (808$ $\left.\mathrm{nm}, 1 \mathrm{~W} / \mathrm{cm}^{2}\right)$ at selected timepoints $(1,5,12,24,48$, and $60 \mathrm{~h})$.

Intracellular DOX release. The cellular uptake of MoOx-PEG-Mel-DOX was studied using confocal laser scanning microscopy (CLSM). 4T1 cells were incubated 
in a 24 -well plate $\left(1 \times 10^{5}\right.$ cells per well in $1 \mathrm{~mL}$ of medium $)$ and cultured for $24 \mathrm{~h}$ at $37^{\circ} \mathrm{C}$ and $5 \% \mathrm{CO}_{2}$. The media was aspirated and a suspension of PBS, free DOX, MoOxPEG-Mel-DOX $(150 \mu \mathrm{L}$, final DOX concentration $=5 \mu \mathrm{g} / \mathrm{mL})$ was added, with or without the application of NIR irradiation, and the cells were further incubated in DMEM for $3 \mathrm{~h}$. Next, the cells were washed three times with PBS (1 mL, pH 7.4) for 10 min per rinse. The cell nuclei were DAPI-stained and fluorescent images were obtained on an Eclipse Ti-S microscope (Nikon Ltd, Japan). The intracellular fluorescence of DOX was also quantified by flow cytometry.

In vitro cell viability. $4 \mathrm{~T} 1$ cells were seeded in DMEM medium supplemented with $10 \% \mathrm{v} / \mathrm{v}$ FBS, $1 \% \mathrm{v} / \mathrm{v}$ streptomycin and $1 \% \mathrm{v} / \mathrm{v}$ penicillin (“complete DMEM"). The relative cell viabilities were evaluated using the MTT assay. 4T1 cells were cultured in a 96-well plate $\left(1 \times 10^{4}\right.$ cells per well, $150 \mu \mathrm{L}$ of medium $)$ and the cells incubated for $24 \mathrm{~h}$ at $37{ }^{\circ} \mathrm{C}$ and $5 \% \mathrm{CO}_{2}$. The medium was then aspirated and the cells washed with PBS. Next, $150 \mu \mathrm{L}$ of suspensions of $\mathrm{MoO}_{\mathrm{x}}-\mathrm{PEG}-\mathrm{Mel}$ and $\mathrm{MoO}_{\mathrm{x}}-\mathrm{PEG}$ in complete DMEM were added to give final concentrations of $0,1,5,10,50,100$ and $200 \mu \mathrm{g} / \mathrm{mL}$, and the cells incubated for another $24 \mathrm{~h}$. The medium was removed, MTT solution (20 $\mu \mathrm{L} ; 5 \mathrm{mg} / \mathrm{mL}$ ) added to each well, and the plate incubated for $4 \mathrm{~h}$. The supernatant was aspirated, and dimethylsulfoxide (DMSO, $150 \mu \mathrm{L}$ ) added to each well to dissolve any formazan crystals which had formed. After $20 \mathrm{~min}$, the absorbance at $570 \mathrm{~nm}$ was quantified using a microplate reader (MULTISKAN MK3, ThermoFisher). Three independent experiments were performed with five replicates in each.

Synergistic effects in vitro. 4T1 cells in complete DMEM were seeded in 96-well 
plates at $1 \times 10^{4}$ cells/well $(150 \mu \mathrm{L} /$ well $)$ and incubated for $24 \mathrm{~h}$ at $5 \% \mathrm{CO}_{2} / 37^{\circ} \mathrm{C}$. The cells were then exposed to four different treatments: PBS+NIR, $\mathrm{MoO}_{\mathrm{x}}-\mathrm{PEG}+\mathrm{NIR}$, $\mathrm{MoO}_{\mathrm{x}}-\mathrm{PEG}-\mathrm{Mel}+\mathrm{NIR}$, free $\mathrm{DOX}$ and $\mathrm{MoO}_{\mathrm{x}}-\mathrm{PEG}-\mathrm{Mel}-\mathrm{DOX}$ with or without laser irradiation. The MTT assay was used to quantify relative cell viabilities. The concentrations of free DOX were set as $0.01,0.1,1,5,10 \mu \mathrm{g} / \mathrm{mL}$, and the $\mathrm{MoO}_{\mathrm{x}}$ systems were added in amounts to give equivalent DOX concentrations. In the case of treatments without DOX, the same mass of nanosheets as with $\mathrm{MoO}_{\mathrm{x}}-\mathrm{PEG}-\mathrm{Mel}-\mathrm{DOX}$ was used. Suspensions or solutions of the drug were added to the pre-incubated cells after aspiration. After a further $24 \mathrm{~h}$ of incubation, the treatment medium was aspirated, before the cells were washed with PBS. Fresh DMEM $(150 \mu \mathrm{L})$ was then added. In the case of the NIR treatments, the cells were irradiated under an $808 \mathrm{~nm}$ laser $\left(1.0 \mathrm{~W} / \mathrm{cm}^{2}\right)$ for $5 \mathrm{~min}$ at this point. In all cases, after washing the cells were incubated in complete DMEM for another $24 \mathrm{~h}$. Cell viability was then determined through the MTT assay (three independent experiments, five replicates in each).

Confocal microscopy. Confocal experiments were performed with 4T1 cells exposed to the following treatments: $\mathrm{PBS}+\mathrm{NIR}, \mathrm{MoO}_{\mathrm{x}}-\mathrm{PEG}+\mathrm{NIR}, \mathrm{MoO}_{\mathrm{x}}-\mathrm{PEG}-$ Mel+NIR, free DOX, and $\mathrm{MoO}_{\mathrm{x}}$-PEG-Mel-DOX with or without NIR. 4T1 cells were seeded in a 24 -well plate for $24 \mathrm{~h}$ at $37{ }^{\circ} \mathrm{C} / 5 \% \mathrm{CO}_{2}\left(1 \times 10^{4}\right.$ cells/well, $150 \mu \mathrm{L}$ of medium). The culture medium was removed and fresh medium containing $\mathrm{MoO}_{\mathrm{x}}-\mathrm{PEG}$, $\mathrm{MoO}_{\mathrm{x}}$-PEG-Mel, free DOX $(0.1 \mu \mathrm{g} / \mathrm{mL})$ and $\mathrm{MoO}_{\mathrm{x}}$-PEG-Mel-DOX (with equivalent DOX concentrations of $0.1 \mu \mathrm{g} / \mathrm{mL}$ ) added, before the cells were incubated for another $24 \mathrm{~h}$. The 4T1 cells were next washed with PBS and complete DMEM medium (150 
$\mu \mathrm{L})$ was then added. Where required, the cells were exposed to a laser $(808 \mathrm{~nm}, 1$ $\mathrm{W} / \mathrm{cm}^{2}$ ) for $5 \mathrm{~min}$ at this point. After $2 \mathrm{~h}$ incubation, the $4 \mathrm{~T} 1$ cells were stained with $\mathrm{CA}$ and PI for 15 min and imaged with a confocal fluorescence microscope (FV1000 instrument, Olympus).

In vivo experiments. All animal experimental procedures were undertaken following the National Institutes of Health Animal Care and Use Committee protocol. The Animal Care and Use Committee of Fudan University reviewed the experimental protocols prior to work beginning and granted ethical approval for all experiments . Female athymic nude mice aged 4-6 weeks were obtained from Nanjing PengSheng Biological Technology Co., Ltd and injected with $1 \times 10^{6} 4 \mathrm{~T} 1$ cells $(100 \mu \mathrm{L}$ of cell suspension). When the tumor volumes (calculated as $\mathrm{V}=\mathrm{W}^{2} \times \mathrm{L} / 2$, where $\mathrm{L}$ and $\mathrm{W}$ denote the length width and width of the tumor) reached $50 \mathrm{~mm}^{3}$ the animals were divided randomly into 5 treatment groups $\left(\mathrm{n}=5\right.$ per group) as follows: saline, $\mathrm{MoO}_{\mathrm{x}}-\mathrm{PEG}-$ Mel+NIR, free DOX, $\mathrm{MoO}_{\mathrm{x}}-\mathrm{PEG}-\mathrm{Mel}-\mathrm{DOX}$ and $\mathrm{MoO}_{\mathrm{x}}-\mathrm{PEG}-\mathrm{Mel}-\mathrm{DOX}+\mathrm{NIR}$ at 3 $\mathrm{mg} / \mathrm{kg}$ equivalent concentrations of DOX. In the $\mathrm{MoO}_{\mathrm{x}}-\mathrm{PEG}-\mathrm{Mel}+\mathrm{NIR}$ group, the same mas of nanosheets as for the $\mathrm{MoO}_{\mathrm{x}}$-PEG-Mel-DOX groups was used. $24 \mathrm{~h}$ after injection, the mice were anesthetized and the animals in the NIR groups were irradiated with an $808 \mathrm{~nm}$ laser $\left(1 \mathrm{~W} / \mathrm{cm}^{2}\right)$ for $10 \mathrm{~min}$ at the tumor site. Tumor volumes and animal body weights were recorded every three days after irradiation and the survival curves evaluated by Kaplan-Meier analysis ${ }^{57}$.

Histological analysis. After a treatment period of 21 days, the mice were euthanized by carbon dioxide asphyxiation and the major organs were harvested. The tumors and 
organs were fixed in $10 \%$ formalin, embedded in paraffin, and stained with H\&E. The sections were then studied using a digital microscope (Leica Qwin). Terminal deoxynucleotidyl transferase dUTP nick end labeling (TUNEL) staining was employed to explore the cellular death processes in the tumor according to the manufacturer's instructions.

Biodistribution study. Female athymic nude mice aged 4-6 weeks bearing 4T1 murine breast cancer tumors were sacrificed at selected time points after the intravenous injection of MoOx-PEG-Mel-DOX $(200 \mu \mathrm{L}, 20 \mathrm{mg} / \mathrm{kg})$. Sacrifices (four mice per time point) took place on one, three and seven days after administration. The major organs (heart, liver, spleen, lungs, kidneys, stomach, intestine, bone, muscle, skin) were harvested and then solubilized in aqua regia. The biodistribution of MoOx-PEG-MelDOX was investigated by quantifying the concentration of Mo in the using inductively coupled plasma atomic emission spectroscopy (ICP-AES), and is presented as the percentage of injected dose per gram of blood ( $\% \mathrm{ID} / \mathrm{g})$.

Statistical analysis. All experiments were repeated at least three times. Data are shown as mean \pm standard deviation (S.D.). The Origin 8.5 software was used to perform statistical analysis. A Student's t-test was used to compare two independent groups of data, and statistical significance was considered to be reached at $\mathrm{P}<0.05$ (*), $\mathrm{P}<0.01(* *)$ and $\mathrm{P}<0.001(* * *)$. 
Graphic abstract 


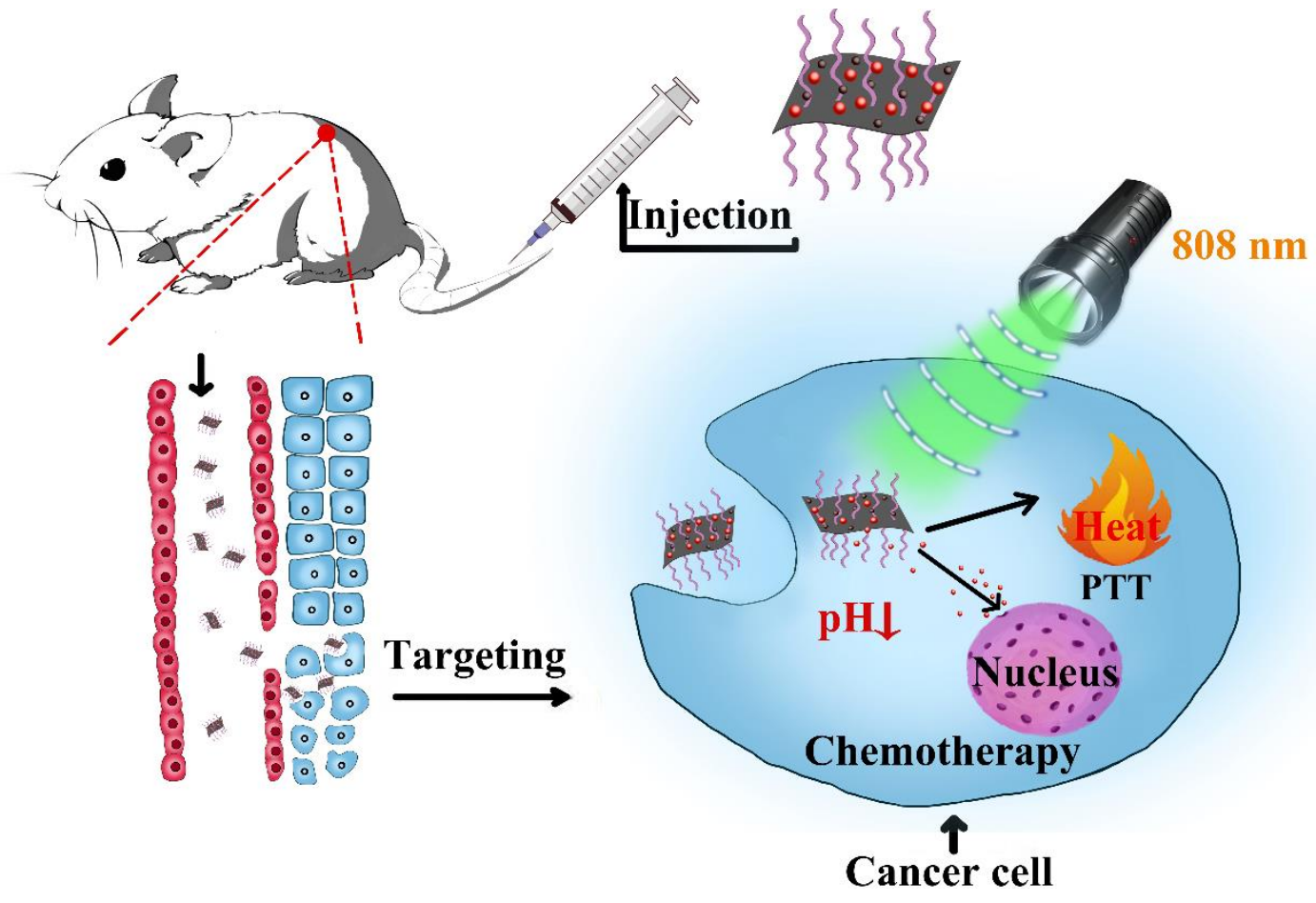



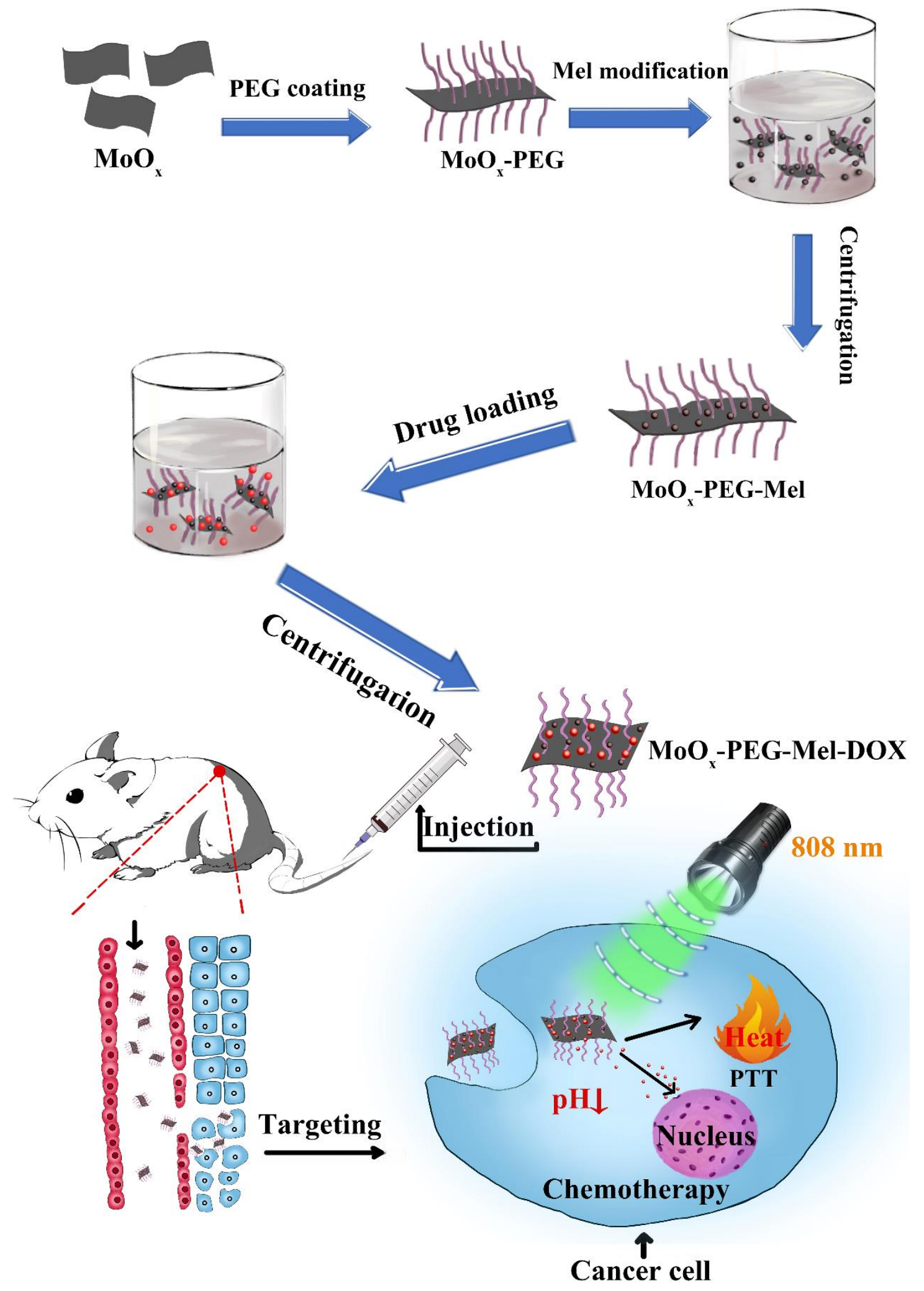

Scheme 1. Construction of the $\mathrm{MoO}_{\mathrm{x}}-\mathrm{PEG}-\mathrm{Mel}-\mathrm{DOX}$ platform for synergistic chemophotothermal therapy. 

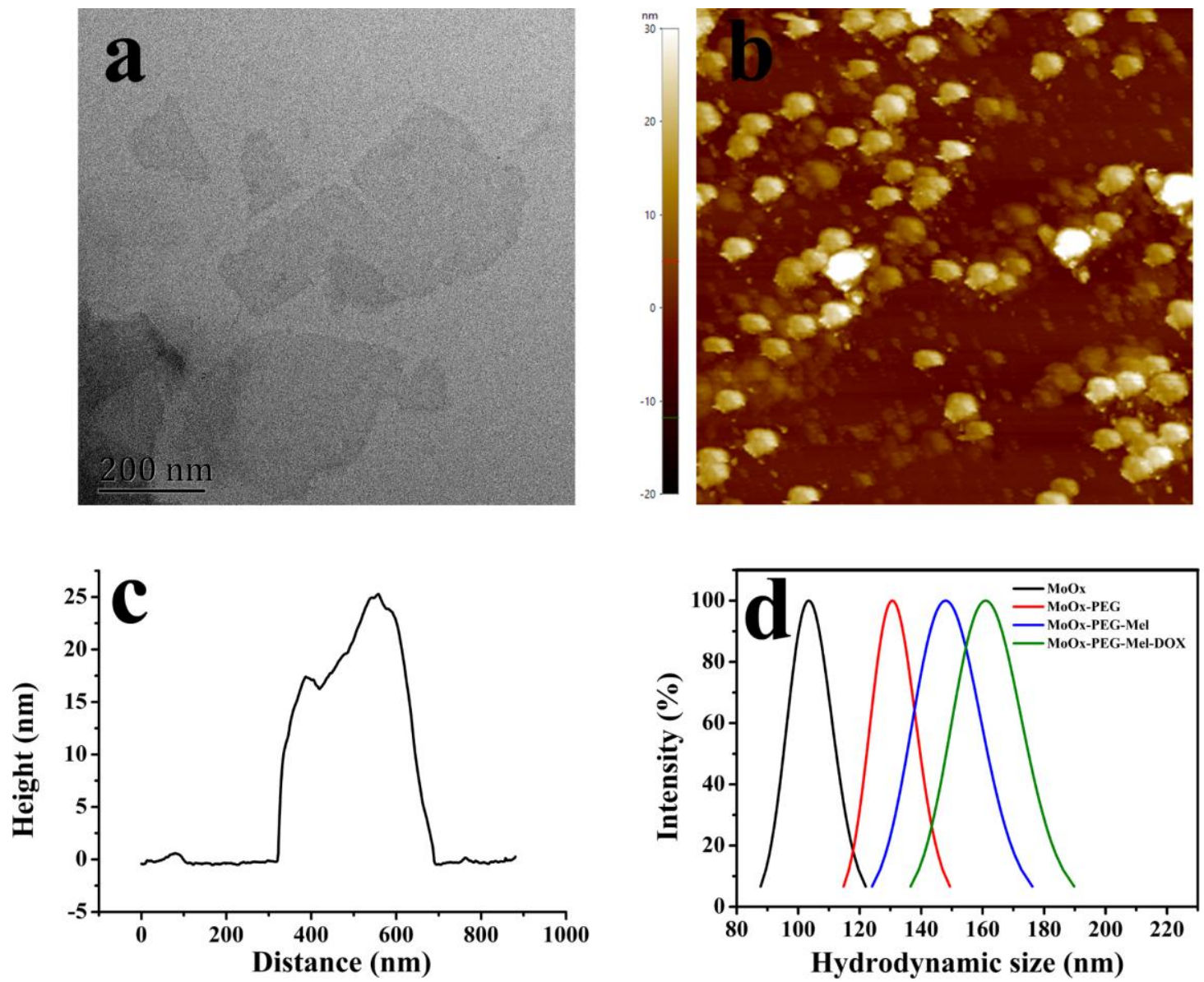

Figure 1. (a) TEM image of the $\mathrm{MoO}_{\mathrm{x}}$ nanosheets. (b) AFM image of $\mathrm{MoO}_{\mathrm{x}}$ with (c) the corresponding AFM height profile. (d) DLS data on $\mathrm{MoO}_{\mathrm{x}}$ and its derivatives.
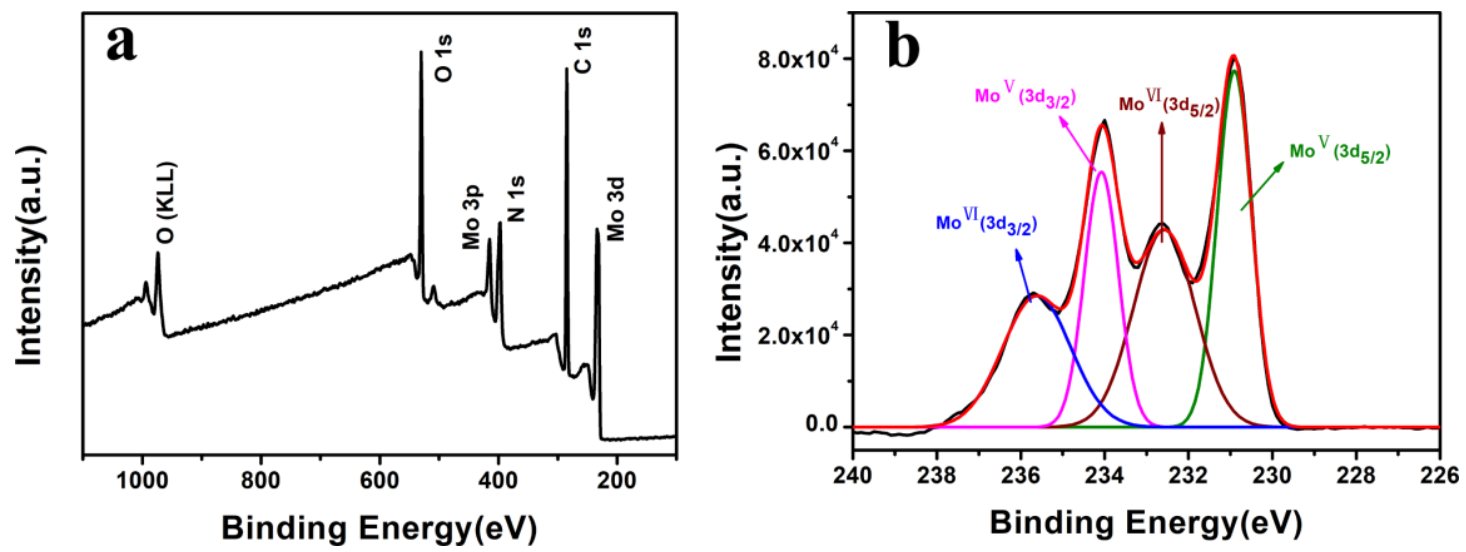

Figure 2. XPS data showing (a) a survey spectrum and (b) the Mo 3d region. 

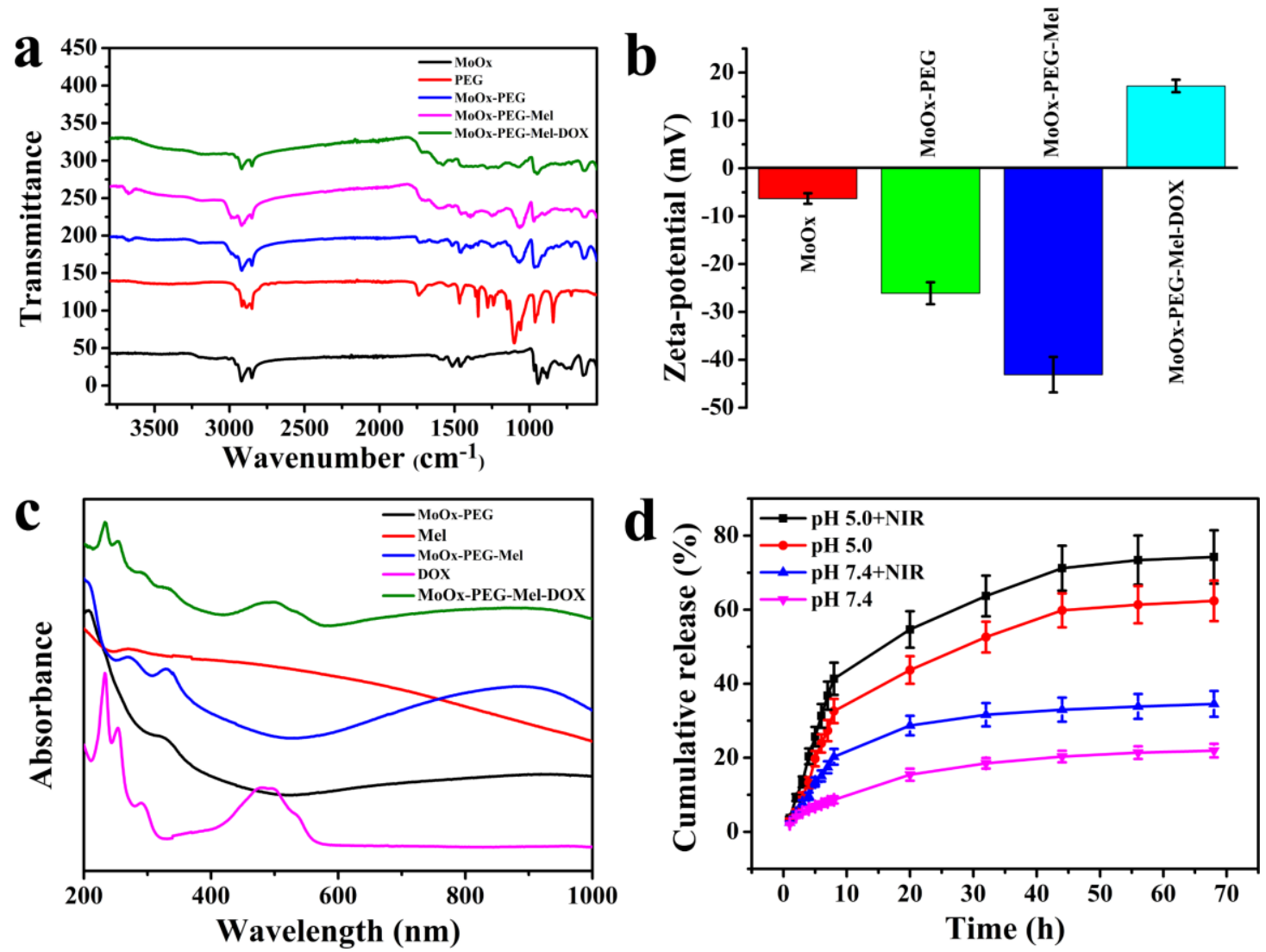

Figure 3. Characterizing data verifying the sequential functionalization steps, and drug release profiles. (a) FT-IR spectra. (b) Zeta potential values $(n=3$, mean \pm S.D.). (c) UV-vis-NIR spectra. (d) DOX release profiles under different $\mathrm{pH}$ values and with or without $808 \mathrm{~nm}$ laser irradiation $\left(1 \mathrm{Wcm}^{-2}\right.$ for $5 \mathrm{~min}$ at $1,5,12,24,48$, and $\left.60 \mathrm{~h}\right)(\mathrm{n}=$ 3, mean \pm S.D.) 

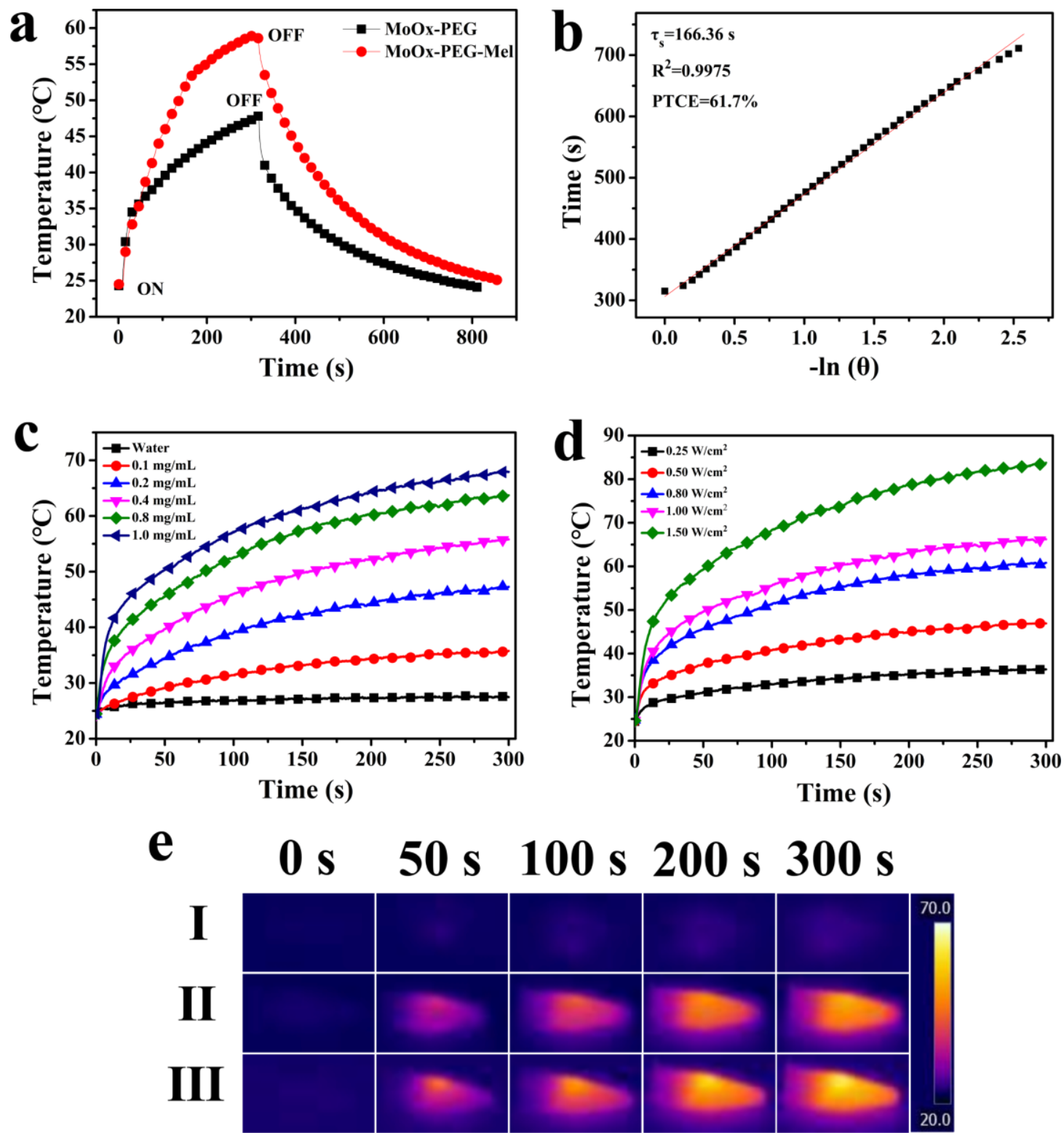

Figure 4. (a) The temperature changes induced in suspensions of $\mathrm{MoO}_{\mathrm{x}}-\mathrm{PEG}$ and $\mathrm{MoO}_{\mathrm{x}}$-PEG-Mel under $808 \mathrm{~nm}$ NIR irradiation. (b) A plot of time vs $\ln (\theta)$ for $\mathrm{MoO}_{\mathrm{x}}-$ PEG-Mel, obtained from the cooling period. (c) Temperature vs time curves for suspensions of $\mathrm{MoO}_{\mathrm{x}}$-PEG-Mel-DOX at different concentrations (laser: $1 \mathrm{~W} \mathrm{~cm}{ }^{-2}, 5$ min). (d) Temperature vs time curves for $\mathrm{MoO}_{\mathrm{x}}-\mathrm{PEG}-\mathrm{Mel}-\mathrm{DOX}$ suspensions $(1 \mathrm{mg} / \mathrm{mL})$ exposed to different laser power densities. (e) Photothermal images of (I) water, (II) $\mathrm{MoO}_{\mathrm{x}}-\mathrm{PEG}$ and (III) MoOx-PEG-Mel $(1 \mathrm{mg} / \mathrm{mL})$ under $808 \mathrm{~nm}$ laser irradiation $(1 \mathrm{~W}$ $\left.\mathrm{cm}^{-2}\right)$. 


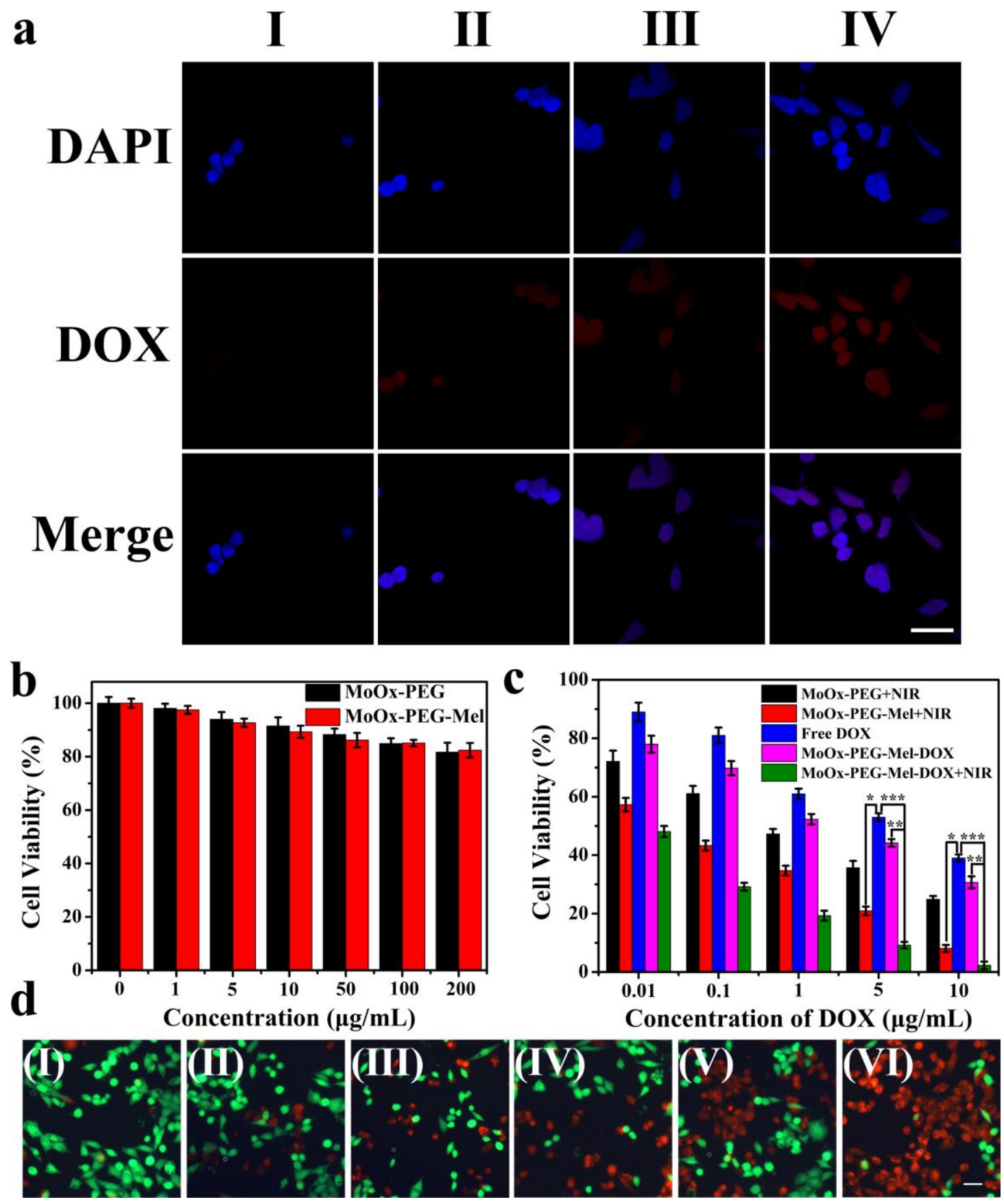

Figure 5. (a) Fluorescence images of $4 \mathrm{~T} 1$ cells incubated with different solutions ( I :

PBS, II : free DOX, III : MoOx-PEG-Mel-DOX and IV : MoOx-PEG-Mel$\mathrm{DOX}+\mathrm{NIR})$. In vitro cell culture results showing the viability of 4T1 cells exposed to (b) various concentrations of $\mathrm{MoO}_{\mathrm{x}}-\mathrm{PEG}$ and $\mathrm{MoO}_{\mathrm{x}}-\mathrm{PEG}-\mathrm{Mel}$; (c) $\mathrm{MoO}_{\mathrm{x}}-\mathrm{PEG}+\mathrm{NIR}$, $\mathrm{MoO}_{\mathrm{x}}$-PEG-Mel+NIR, free DOX, and $\mathrm{MoO}_{\mathrm{x}}$-PEG-Mel-DOX with or without NIR. (d) 
Fluorescence images of 4T1 cells after CA/PI staining: (I) PBS+NIR, (II) free DOX, (III) $\mathrm{MoO}_{\mathrm{x}}$-PEG-Mel-DOX, (IV) $\mathrm{MoO}_{\mathrm{x}}-\mathrm{PEG}+\mathrm{NIR}$, (V) $\mathrm{MoO}_{\mathrm{x}}-\mathrm{PEG}-\mathrm{Mel}+\mathrm{NIR}$, and (VI) MoOx-PEG-Mel-DOX+NIR (all with equivalent concentrations of DOX). Laser power density: $1 \mathrm{~W} \mathrm{~cm}^{-2}$; scale bar: $50 \mu \mathrm{m}$ test. $* *$ denotes $\mathrm{P}<0.01$, and $* * * \mathrm{P}<0.001$ (calculated from a Student's T-test). Three independent experiments were performed with five replicates in each.
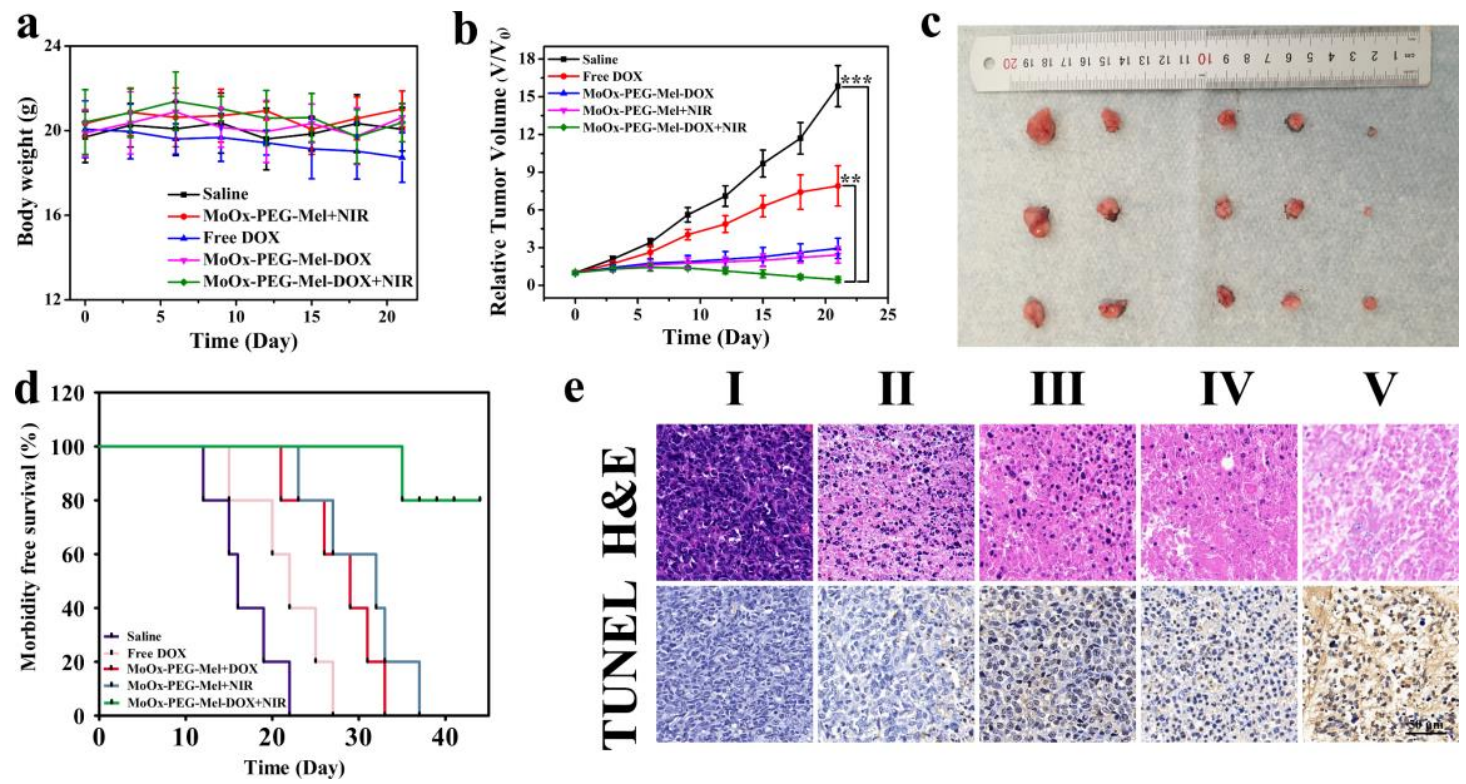

Figure 6. The results of in vivo antitumor efficacy experiments. (a) Average body weight variation with time. (b) The evolution of tumor volume. ${ }^{* *} \mathrm{p}<0.01$, and $* * * \mathrm{p}<$ 0.001 (Student's t test). (c) Representative photographs of tumors exercised on day 21. (d) Kaplan-Meier survival curves. (e) Histological analysis (H\&E staining and TUNEL staining) of tumors from mice receiving (I) control (saline); (II) free DOX; (III) $\mathrm{MoO}_{\mathrm{x}^{-}}$ PEG-Mel-DOX; (IV) $\mathrm{MoO}_{\mathrm{x}}-\mathrm{PEG}-\mathrm{Mel}+\mathrm{NIR}$; and, (V) $\mathrm{MoO}_{\mathrm{x}}$-PEG-Mel-DOX+NIR (Scale bars: $50 \mu \mathrm{m}$ ). 


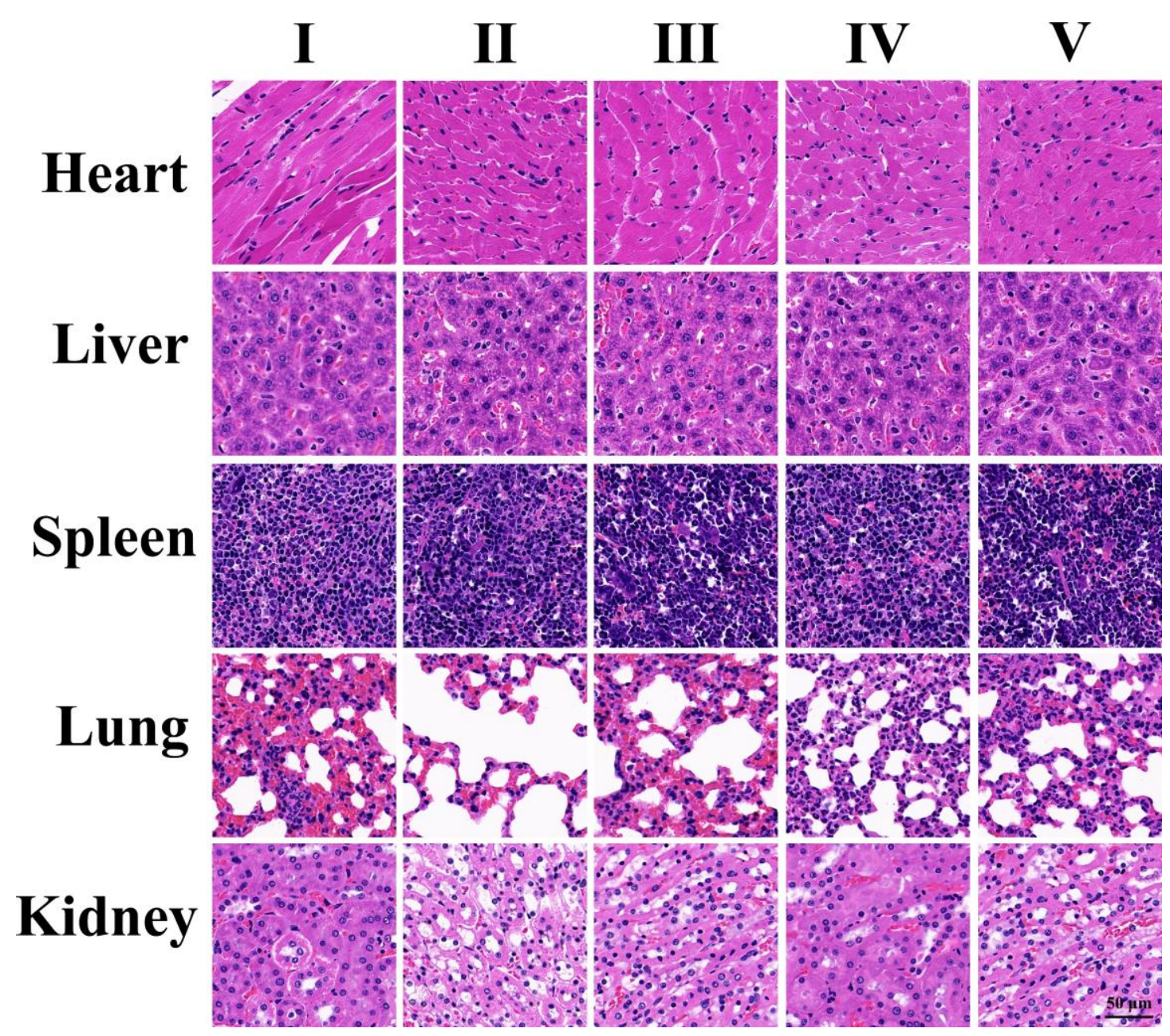

Figure 7. Representative H\&E-stained sections from mice receiving the varied treatments: (I) control (saline); (II) free DOX; (III) $\mathrm{MoO}_{\mathrm{x}}-\mathrm{PEG}-\mathrm{Mel}-\mathrm{DOX}$; (IV) $\mathrm{MoO}_{\mathrm{x}^{-}}$ PEG-Mel+NIR; (V) $\mathrm{MoO}_{\mathrm{x}}-\mathrm{PEG}-\mathrm{Mel}-\mathrm{DOX}+\mathrm{NIR}$. Scale bars: $50 \mu \mathrm{m}$. 


\section{ASSOCIATED CONTENT}

\section{Supporting Information}

XRD patterns of the MoOx nanomaterials, a plot to calculate the PTCE of MoOx-PEG, data showing the photothermal stability of MoOx-PEG-Mel-DOX and optimization of drug loading, the results of a study into cellular uptake by flow cytometry, and the findings from in vivo biodistribution studies in mice.

\section{AUTHOR INFORMATION}

\section{Corresponding Authors}

*E-mail: lzhu@dhu.edu.cn.

*E-mail: 377453507@qq.com.

\section{ORCID}

Li-min Zhu: 0000-0003-2806-7971

\section{Conflict of Interest}

The authors declare no conflict of interest.

\section{ACKNOWLEDGEMENTS}

This research was financially supported by the Shanghai Municipal Science and Technology Commission Project (grant 16410723700), the Outstanding Clinical Discipline Project of Shanghai Pudong (Grant No. PWYgy2018-09), the Biomedical Textile Materials "111 Project" of the China Ministry of Education (No B07024), and 
the UK-China Joint Laboratory for Therapeutic Textiles (based at Donghua University).

\section{REFERENCES}

(1) Ferrari, M. Cancer nanotechnology: opportunities and challenges. Nat. Rev. Cancer 2005, $5,161-171$.

(2) Laura Martínez, M.; Patricia, H. G.; Blanca, D. R.; Julio, R.; Caamano, A. J.; Elisa, C.; Angeles, J.; Francisco, S. R.; José García, S.; Daniel, J. Heating efficiency of multiwalled carbon nanotubes in the first and second biological windows. Nanoscale 2013, $5,7882-7889$.

(3) Lev, D.; Nikolai, K. Gold nanoparticles in biomedical applications: recent advances and perspectives. Chem. Soc. Rev. 2012, 41, 2256-2282.

(4) Li, J.; Hu, Y.; Yang, J.; Wei, P.; Sun, W.; Shen, M.; Zhang, G.; Shi, X. Hyaluronic acid-modified $\mathrm{Fe}_{3} \mathrm{O}_{4} @ \mathrm{Au}$ core/shell nanostars for multimodal imaging and photothermal therapy of tumors. Biomaterials 2015, 38, 10-21.

(5) Li, X.; Xing, L.; Zheng, K.; Wei, P.; Du, L.; Shen, M.; Shi, X. Formation of Gold Nanostar-Coated Hollow Mesoporous Silica for Tumor Multimodality Imaging and Photothermal Therapy. ACS Appl. Mater. Interfaces 2017, 9, 5817-5827. 
(6) Vijayakumar, S.; Selvakumar, S.; Chen-Sheng, Y. Near-infrared light-responsive nanomaterials in cancer therapeutics. Chem. Soc. Rev. 2014, 43, 6254-6287.

(7) Xia, B.; Wang, B.; Shi, J.; Zhang, Y.; Zhang, Q.; Chen, Z.; Li, J. Photothermal and biodegradable polyaniline/porous silicon hybrid nanocomposites as drug carriers for combined chemo-photothermal therapy of cancer. Acta Biomater. 2017, 51, 197-208.

(8) Xianguang, D.; Hao, L. C.; Mengxin, Z.; Renjun, H.; Chunyan, L.; He, S.; Mengya, L.; Yu, Z.; Nan, G.; Zhijun, Z. Surface plasmon resonance enhanced light absorption and photothermal therapy in the second near-infrared window. J. Am. Chem. Soc. 2014, $136,15684-15693$.

(9) Wu, J.; Williams, G. R.; Niu, S.; Gao, F.; Tang, R.; Zhu, L. M. A Multifunctional Biodegradable Nanocomposite for Cancer Theranostics. Adv. Sci. 2019, 10, 1802001.

(10) Kai, Y.; Liangzhu, F.; Xiaoze, S.; Zhuang, L. Nano-graphene in biomedicine: theranostic applications. Chem. Soc. Rev. 2013, 42, 530-547.

(11) Liu, J.; Yu, M.; Zhou, C.; Yang, S.; Ning, X.; Zheng, J. Passive tumor targeting of renal-clearable luminescent gold nanoparticles: long tumor retention and fast normal tissue clearance. J. Am. Chem. Soc. 2013, 135, 4978-4981.

(12) Chen, J.; Li, X.; Liu, X.; Yan, H.; Xie, Z.; Sheng, Z.; Gong, X.; Wang, L.; Liu, X.; Zhang, P. Hybrid MoSe-Indocyanine Green Nanosheets as A High-Efficient Phototheranostic Agent for Photoacoustic Imaging Guided Photothermal Cancer Therapy. Biomater. Sci. 2018, 6, 1503-1516.

(13) Wang, K.; Zhang, Y.; Wang, J.; Yuan, A.; Sun, M.; Wu, J.; Hu, Y. Self-assembled IR780-loaded transferrin nanoparticles as an imaging, targeting and PDT/PTT agent for 
cancer therapy. Sci Rep 2016, 6, 27421.

(14) Lin, H.; Feng, Q.; Wang, Y.; Zhang, H.; Jiang, G.; Yang, X.; Ren, J.; Zhu, X.; Shi, Y.; Zhang, Z. Multifunctional nanosheets based on hyaluronic acid modified graphene oxide for tumor-targeting chemo-photothermal therapy. J. Nanopart. Res. 2015, 17, 162. (15) Teng, L.; Chao, W.; Xing, G.; Hua, G.; Liang, C.; Xiaoze, S.; Liangzhu, F.; Baoquan, S.; Zhuang, L. Drug delivery with PEGylated $\mathrm{MoS}_{2}$ nano-sheets for combined photothermal and chemotherapy of cancer. Adv. Mater. 2014, 26, 3433-3440. (16) Zhang, X.; Wu, J.; Williams, G. R.; Yang, Y.; Niu, S.; Qian, Q.; Zhu, L. M. Dualresponsive molybdenum disulfide/copper sulfide-based delivery systems for enhanced chemo-photothermal therapy. J. Colloid Interface Sci. 2019, 539, 433-441.

(17) Han, X.; Huang, J.; Lin, H.; Wang, Z.; Li, P.; Chen, Y. 2D Ultrathin MXene-Based Drug-Delivery Nanoplatform for Synergistic Photothermal Ablation and Chemotherapy of Cancer. Adv. Healthc. Mater. 2018, 7, 1701394.

(18) Tianyue, J.; Wujin, S.; Qiuwen, Z.; Burns, N. A.; Khan, S. A.; Ran, M.; Zhen, G. Furin-mediated sequential delivery of anticancer cytokine and small-molecule drug shuttled by graphene. Adv. Mater. 2015, 27, 1021-1028.

(19) Liang, C.; Chao, Y.; Sida, S.; Xuan, Y.; Hua, G.; Kai, Y.; Zhuang, L. Bottom-Up Synthesis of Metal-Ion-Doped $\mathrm{WS}_{2}$ Nanoflakes for Cancer Theranostics. ACS Nano 2015, 9, 11090-11101.

(20) Kim, H. Near-infrared light-responsive nanomaterials for cancer theranostics. Wiley Interdiscip. Rev.-Nanomed. Nanobiotechnol. 2016, 8, 23-45.

(21) Bao, T.; Yin, W.; Zheng, X.; Zhang, X.; Yu, J.; Dong, X.; Yong, Y.; Gao, F.; Yan, 
L.; Gu, Z.; Zhao, Y. One-pot synthesis of PEGylated plasmonic $\mathrm{MoO}_{(3-\mathrm{x})}$ hollow nanospheres for photoacoustic imaging guided chemo-photothermal combinational therapy of cancer. Biomaterials 2016, 76, 11-24.

(22) Kai, D.; Zhen, L.; Zhenhua, L.; Jinsong, R.; Xiaogang, Q. Hydrophobic anticancer drug delivery by a $980 \mathrm{~nm}$ laser-driven photothermal vehicle for efficient synergistic therapy of cancer cells in vivo. Adv. Mater. 2013, 25, 4452-4458.

(23) Faucheaux, J. A.; Stanton, A. L.; Jain, P. K. Plasmon Resonances of Semiconductor Nanocrystals: Physical Principles and New Opportunities. J. Phys. Chem. Lett. 2014, 5, 976-985.

(24) Marin, B. C.; Hsu, S. W.; Li, C.; Lo, A.; Zwissler, D. W.; Liu, Z.; Tao, A. R. Plasmon-Enhanced Two-Photon Absorption in Photoluminescent Semiconductor Nanocrystals. ACS Photonics 2016, 3, 526-531.

(25) Murray, W. A.; Barnes, W. L. Plasmonic materials. Adv. Mater. 2007, 19, 37713782.

(26) Liu, W.; Li, X.; Li, W.; Zhang, Q.; Bai, H.; Li, J.; Xi, G. Highly stable molybdenum dioxide nanoparticles with strong plasmon resonance are promising in photothermal cancer therapy. Biomaterials 2018, 163, 43-54.

(27) Yin, W.; Bao, T.; Zhang, X.; Gao, Q.; Yu, J.; Dong, X.; Yan, L.; Gu, Z.; Zhao, Y. Biodegradable MoOx nanoparticles with efficient near-infrared photothermal and photodynamic synergetic cancer therapy at the second biological window. Nanoscale 2018, 10, 1517-1531.

(28) Riley, P. A. Melanin. Int. J. Biochem. Cell Biol. 1997, 29, 1235-1239. 
(29) Yanlan, L.; Kelong, A.; Jianhua, L.; Mo, D.; Yangyang, H.; Lehui, L. Dopaminemelanin colloidal nanospheres: an efficient near-infrared photothermal therapeutic agent for in vivo cancer therapy. Adv. Mater. 2013, 25, 1353-1359.

(30) Jiang, Q.; Luo, Z.; Men, Y.; Yang, P.; Peng, H.; Guo, R.; Tian, Y.; Pang, Z.; Yang, W. Red blood cell membrane-camouflaged melanin nanoparticles for enhanced photothermal therapy. Biomaterials 2017, 143, 29-45.

(31) Cho, S.; Park, W.; Kim, D. H. Silica-Coated Metal Chelating-Melanin Nanoparticles as a Dual-Modal Contrast Enhancement Imaging and Therapeutic Agent. ACS Appl. Mater. Interfaces 2017, 9, 101-111.

(32) Xiaoxin, Q.; Sida, S.; Teng, L.; Liang, C.; Zhuang, L. Two-dimensional $\mathrm{TiS}_{2}$ nanosheets for in vivo photoacoustic imaging and photothermal cancer therapy. Nanoscale 2015, 7, 6380-6387.

(33) Song, G.; Hao, J.; Liang, C.; Liu, T.; Gao, M.; Cheng, L.; Hu, J.; Liu, Z. Degradable Molybdenum Oxide Nanosheets with Rapid Clearance and Efficient Tumor Homing Capabilities as a Therapeutic Nanoplatform. Angew. Chem.-Int. Edit. 2016, 55, 21222126.

(34) Ainwar, M.; Hogarth, C. A.; Theocharis, C. R. A study of the infrared absorption spectra of thin amorphous films of molybdenum trioxide. J. Mater. Sci. 1989, 24, 23872390.

(35) Bhosle, V.; Tiwari, A.; Narayan, J. Epitaxial growth and properties of $\operatorname{MoOx}(2<\mathrm{x}<2.75)$ films. J. Appl. Phys. 2005, 97, 083539.

(36) Katrib, A.; Petit, C.; Légaré, P.; Hilaire, L.; Maire, G. An investigation of metal- 
support interaction in bimetallic Pt-Mo catalysts deposited on silica and alumina. Surf. Sci. 1987, 189, 886-893.

(37) Kumar, V.; Wang, X.; Lee, P. S. Synthesis of pyramidal and prismatic hexagonal $\mathrm{MoO}_{3}$ nanorods using thiourea. Crystengcomm 2013, 15, 7663-7669.

(38) Pandey, S.; Sharma, K. H.; Sharma, A. K.; Nerthigan, Y.; Hang, D. R.; Wu, H. F. Comparative Photothermal Performance among Various Sub-Stoichiometric 2D Oxygen-Deficient Molybdenum Oxide Nanoflakes and In Vivo Toxicity. Chem.-Eur. J. 2018, 24, 7417-7427.

(39) Song, G.; Shen, J.; Jiang, F.; Hu, R.; Li, W.; An, L.; Zou, R.; Chen, Z.; Qin, Z.; Hu, J. Hydrophilic molybdenum oxide nanomaterials with controlled morphology and strong plasmonic absorption for photothermal ablation of cancer cells. ACS Appl. Mater. Interfaces 2014, 6, 3915-3922.

(40) Wongkrua, P.; Thongtem, T.; Thongtem, S. Synthesis of h- and $\alpha-\mathrm{MoO}_{3}$ by Refluxing and Calcination Combination: Phase and Morphology Transformation, Photocatalysis, and Photosensitization. J. Nanomater. 2013, 8, 702679.

(41) Zhan, Y.; Liu, Y.; Zu, H.; Guo, Y.; Wu, S.; Yang, H.; Liu, Z.; Lei, B.; Zhuang, J.; Zhang, X.; Huang, D.; Hu, C. Phase-controlled synthesis of molybdenum oxide nanoparticles for surface enhanced Raman scattering and photothermal therapy. Nanoscale 2018, 10, 5997-6004.

(42) Zhang, X.; Wu, J.; Williams, G. R.; Niu, S.; Qian, Q.; Zhu, L. M. Functionalized $\mathrm{MoS}_{2}$-nanosheets for targeted drug delivery and chemo-photothermal therapy. Colloid Surf. B-Biointerfaces 2019, 173, 101-108. 
(43) Jin, J.; Guo, M.; Liu, J.; Liu, J.; Zhou, H.; Li, J.; Wang, L.; Liu, H.; Li, Y.; Zhao,

Y.; Chen, C. Graphdiyne Nanosheet-Based Drug Delivery Platform for Photothermal/Chemotherapy Combination Treatment of Cancer. ACS Appl. Mater. Interfaces 2018, 10, 8436-8442.

(44) Xu, Y.; Hu, X.; Guan, P.; Du, C.; Tian, Y.; Ding, S.; Li, Z.; Yan, C. A novel controllable molecularly imprinted drug delivery system based on the photothermal effect of graphene oxide quantum dots. J. Mater. Sci. 2019, 54, 9124-9139.

(45) Wu, P.; Wang, X.; Wang, Z.; Ma, W.; Guo, J.; Chen, J.; Yu, Z.; Li, J.; Zhou, D. Light-Activatable Prodrug and AIEgen Copolymer Nanoparticle for Dual-Drug Monitoring and Combination Therapy. ACS Appl. Mater. Interfaces 2019, 11, 1869118700.

(46) Cheng, Y.-J.; Qin, S.-Y.; Ma, Y.-H.; Chen, X.-S.; Zhang, A.-Q.; Zhang, X.-Z. Super-pH-Sensitive Mesoporous Silica Nanoparticle-Based Drug Delivery System for Effective Combination Cancer Therapy. ACS Biomater. Sci. Eng. 2019, 5, 1878-1886. (47) Liu, T.; Wang, C.; Gu, X.; Gong, H.; Cheng, L.; Shi, X.; Feng, L.; Sun, B.; Liu, Z. Drug delivery with PEGylated $\mathrm{MoS}_{2}$ nano-sheets for combined photothermal and chemotherapy of cancer. Adv. Mater. 2014, 26, 3433-3440.

(48) Niu, S.; Bremner, D. H.; Wu, J.; Wu, J.; Wang, H.; Li, H.; Qian, Q.; Zheng, H.; Zhu, L. 1-Peptide functionalized dual-responsive nanoparticles for controlled paclitaxel release and enhanced apoptosis in breast cancer cells. Drug Deliv. 2018, 25, 1275-1288. (49) Chen, Y. W.; Su, Y. L.; Hu, S. H.; Chen, S. Y. Functionalized graphene nanocomposites for enhancing photothermal therapy in tumor treatment. Adv. Drug 
Deliv. Rev. 2016, 105, 190-204.

(50) Tao, W.; Ji, X.; Xu, X.; Islam, M. A.; Li, Z.; Chen, S.; Saw, P. E.; Zhang, H.;

Bharwani, Z.; Guo, Z.; Shi, J.; Farokhzad, O. C. Antimonene Quantum Dots: Synthesis and Application as Near-Infrared Photothermal Agents for Effective Cancer Therapy. Angew. Chem.-Int. Edit. 2017, 56, 11896-11900.

(51) Xie, Z.; Wang, D.; Fan, T.; Xing, C.; Li, Z.; Tao, W.; Liu, L.; Bao, S.; Fan, D.; Zhang, H. Black phosphorus analogue tin sulfide nanosheets: synthesis and application as near-infrared photothermal agents and drug delivery platforms for cancer therapy. $J$. Mat. Chem. B 2018, 6, 4747-4755.

(52) Chen, Y.; Z, F.; Z, Z.; W, N.; C, L.; N, Y.; B, C.; H, Z. Two-Dimensional Metal Nanomaterials: Synthesis, Properties, and Applications. Chem. Rev. 2018, 118, 64096455.

(53) Fan, W.; Yung, B.; Huang, P.; Chen, X. Nanotechnology for Multimodal Synergistic Cancer Therapy. Chem. Rev. 2017, 117, 13566-13638.

(54) Niu, S.; Williams, G. R.; Wu, J.; Wu, J.; Zhang, X.; Zheng, H.; Li, S.; Zhu, L.-M. A novel chitosan-based nanomedicine for multi-drug resistant breast cancer therapy. Chem. Eng. J. 2019, 369, 134-149.

(55) Ding, D.; Guo, W.; Guo, C.; Sun, J.; Zheng, N.; Wang, F.; Yan, M.; Liu, S. $\mathrm{MoO}_{3-}$ x quantum dots for photoacoustic imaging guided photothermal/photodynamic cancer treatment. Nanoscale 2017, 9, 2020-2029.

(56) Lu, N.; Huang, P.; Fan, W.; Wang, Z.; Liu, Y.; Wang, S.; Zhang, G.; Hu, J.; Liu, W.; Niu, G. Tri-stimuli-responsive biodegradable theranostics for mild hyperthermia 
enhanced chemotherapy. Biomaterials 2017, 126, 39-48.

(57) Martinez-Garcia, M.; Vargas-Barron, J.; Banuelos-Tellez, F.; Gonzalez-Pacheco, H.; Fresno, C.; Hernandez-Lemus, E.; Martinez-Rios, M. A.; Vallejo, M. Public insurance program impact on catastrophic health expenditure on acute myocardial infarction. Public Health 2018, 158, 47-54. 